\title{
Hub Loads Analysis of the SA349/2 Helicopter
}

R.M. Heffernan, G.K. Yamauchi, M. Gaubert, and $W$. Johnson

(AASA-TH-101061) HOB LOADS ANALYSIS OE THE
SA349/2 HELICCPIEE (BASA) $40 \mathrm{p}$ CSCLOIC

$889-13410$

Unclas

G3/02 0183255

December 1988

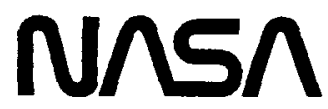

National Aeronautics and

Space Administration 


\section{Hub Loads Analysis of the SA349/2 Helicopter}

R.M. Heffernan

G.K. Yamauchi, Ames Research Center, Moffett Field, California

M. Gaubert, Aerospatiale - Division Helicopteres, Marignane, France

W. Johnson, Johnson Aeronautics, Palo Alto, California

National Aeronautics and

Space Administration

Ames Research Center

Moffett Field, California 94035 
The forces and moments at the rotor hub of an Aerospatiale SA349/2 helicopter were investigated. The study included three main topics. First, measured hub forces and moments for a range of level flight conditions ( $\mu=0.14$ to 0.37 ) were compared with predictions from a comprehensive rotorcraft analysis to examine the influence of the wake model on the correlations. Second, the effect of changing the blade mass distribution and blade chordwise center of gravity location on the $3 / \mathrm{rev}$ nonrotating frame hub loads was studied for a high-speed flight condition $(\mu=0.37)$. Third, the use of higher harmonic control to reduce nonrotating frame $3 / \mathrm{rev}$ hub shear forces was investigated. The last two topics were theoretical studies only.

\section{Nomenclature}

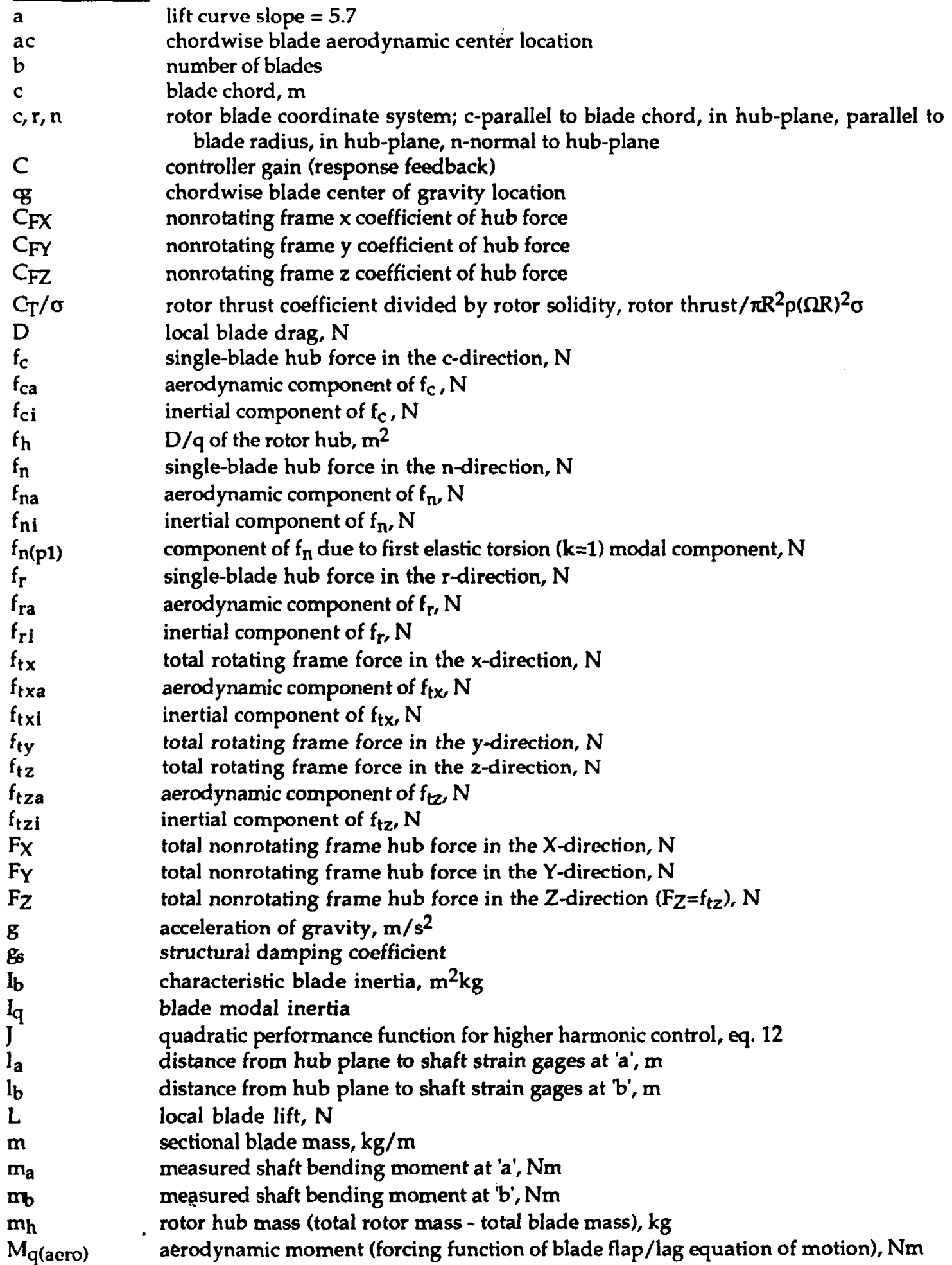




\begin{tabular}{|c|c|}
\hline$m_{t x}$ & total rotating frame hub moment in the $\mathrm{x}$-direction, $\mathrm{Nm}$ \\
\hline $\mathrm{m}_{\mathrm{ty}}$ & total rotating frame hub moment in the $\mathrm{y}$-direction, $\mathrm{Nm}$ \\
\hline$m_{t z}$ & total rotating frame hub moment in the $\mathrm{z}$-direction, $\mathrm{Nm}$ \\
\hline $\mathrm{Mx}$ & total nonrotating frame hub moment in the $\mathrm{X}$-direction, $\mathrm{Nm}$ \\
\hline MY & total nonrotating frame hub moment in the Y-direction, $\mathrm{Nm}$ \\
\hline $\mathrm{MZ}_{\mathrm{Z}}$ & total nonrotating frame hub moment in the $Z$-direction $\left(M_{Z}=m_{t z}\right), N m$ \\
\hline $\mathrm{p}$ & generalized blade torsion degree of freedom \\
\hline $\begin{array}{l}\mathrm{q} \\
\mathrm{R}\end{array}$ & generalized blade bending degree of freedom \\
\hline R & $\begin{array}{l}\text { rotor radius }=5.25 \mathrm{~m} \\
\text { blade radial location } \mathrm{m}\end{array}$ \\
\hline $\mathrm{S}_{\mathrm{ql}}$ & blade lag inertial constant \\
\hline $\mathrm{S}_{\mathrm{qf}}$ & blade flap inertial constant \\
\hline $\mathbf{T}$ & transfer-function matrix \\
\hline$u_{r}$ & component of local blade velocity along radius (normal to the $\mathrm{c}-\mathrm{n}$ plane), $\mathrm{m} / \mathrm{s}$ \\
\hline $\mathrm{U}$ & local blade velocity, $\mathrm{m} / \mathrm{s}$ \\
\hline $\mathrm{V}_{0}$ & flight velocity, $\mathrm{m} / \mathrm{s}$ \\
\hline $\begin{array}{l}x, y, z \\
X, Y, Z\end{array}$ & $\begin{array}{l}\text { rotating frame shaft axis system } \\
\text { nonrotating frame shaft axis system }\end{array}$ \\
\hline $\mathbf{z}$ & vector of harmonics of response variables, eq. 10 \\
\hline$\alpha$ & blade angle of attack, deg \\
\hline$\alpha_{s}$ & shaft angle of attack, deg \\
\hline$\beta_{1 c}$ & longitudinal flap angle, deg \\
\hline$\eta_{1}$ & lag bending mode shape \\
\hline$\eta_{f}$ & flap bending mode shape \\
\hline$\phi$ & induced angle of the resultant air velocity in the c-n plane, deg \\
\hline$\gamma$ & lock number, pack ${ }^{4} / I_{b}$ \\
\hline$\mu$ & advance ratio $=V_{0} / \Omega R$ \\
\hline $\mathbf{v}$ & blade bending modal frequency, $1 /$ rev \\
\hline$\Psi$ & blade azimuth angle, measured from tail boom toward advancing side of rotor disk, deg \\
\hline$\rho$ & air density, $\mathrm{kg} / \mathrm{m} 3$ \\
\hline$\sigma$ & solidity, bc/ $\pi R$ \\
\hline$\theta_{0}$ & collective pitch, deg \\
\hline$\theta_{\mathrm{c}}$ & lateral cyclic pitch, deg \\
\hline$\theta_{\text {can }}$ & vector of harmonics of control variables (fixed-frame), deg \\
\hline$\theta_{\mathbf{e}}$ & elastic pitch, deg \\
\hline$\theta_{\mathrm{HHC}}$ & HHC control vector (rotating frame), deg \\
\hline$\theta_{\mathrm{p}}$ & pilot control input, deg \\
\hline$\theta_{\mathrm{s}}$ & longitudinal cyclic pitch, deg \\
\hline$\xi$ & torsion mode shape \\
\hline$\Omega$ & rotor rotation rate, $\mathrm{rad} / \mathrm{sec}$ \\
\hline \multicolumn{2}{|c|}{ Subscripts } \\
\hline c & cosine component \\
\hline $\mathbf{i}$ & $\begin{array}{l}\text { harmonic number } \\
\text { mode number }\end{array}$ \\
\hline $\mathrm{n}$ & harmonic number \\
\hline $\mathbf{s}$ & sine component \\
\hline
\end{tabular}

\section{Introduction}

Reducing helicopter vibration is desirable for many reasons, including increased crew and passenger comfort, and reduced wear on the aircraft. An understanding of the sources which generate vibration can aid in the development of rotorcraft with lower oscillatory loads. Examining helicopter forces and moments at the rotor hub, both experimentally and theoretically, is an important step toward understanding vibration. With this in mind, three aspects of hub loads were studied. The first topic of the paper compares predicted and measured hub loads in both the rotating and nonrotating frame. Predictions were made using both a uniform inflow and a nonuniform inflow (prescribed wake) model to determine the effect of the wake model on the correlations. The second topic investigates how 
variations in the blade mass distribution and chordwise cg location influenced the SA349/2 oscillatory hub loads. The topic of altering blade design to reduce hub loads has been investigated both experimentally and analytically. References 1-8 address the effects of torsional stiffness, tip sweep, camber, chordwise cg offset (relative to the ac axis), blade mass distribution, twist, blade bending stiffness, and tab deflections on hub vibration and blade vibratory loads of four-bladed articulated rotors. This paper concentrates on predicting and studying the oscillatory hub loads of a three-bladed helicopter. The third topic investigates using higher harmonic control $(\mathrm{HHC})$ of the rotor to minimize the hub shear forces. The last two topics were strictly theoretical investigations.

This effort represents the second phase of a cooperative program between the National Aeronautics and Space Administration (NASA) and the French Ministry of Defense. The purpose of this program is to learn more about the aerodynamic and dynamic behavior of helicopters using SA349/2 flight test data and current helicopter analyses developed in the United States and in France. The first phase began with the 1984 flight test of the SA349/2 helicopter. Rotor blade structural and aerodynamic loads were measured for various thrust levels and advance ratios. Reference 9 presents the flight test data, and includes a description of the data acquisition and reduction procedures. References 10 and 11 present correlations between analyses and the aerodynamic and structural data. The effects of wake geometry, dynamic stall model, transonic aerodynamics, and different methods of calculating the blade elastic response were investigated. Reference 12 concentrated on the effect of individual blade modes on blade aerodynamic and structural loads. Reference 13 validated a new method of computing the forced response of an elastic blade using the measured aerodynamic loads

The SA349/2 aircraft was flown again in 1987, thus initiating the second phase of this joint program. For this flight test, the rotor mast was instrumented to measure hub forces and moments. More detailed blade bending moment data were also obtained. Several 1984 flight conditions were duplicated during the 1987 flight tests by matching $\mu$ and $C_{T} / \sigma$. For these duplicated conditions data for blade aerodynamic and structural loads, hub loads, and rotor flapping angle and shaft angle are available. Collectively, results from the two flight tests provide a comprehensive data base. Data from the 1987 flight test are documented in ref. 14.

\section{SA349/2 Flight Test Data}

The SA349/2 aircraft, fully described in ref. 9, has an advanced geometry main rotor and three Grande Vitesse blades with rectangular tips. During the 1987 flight test, the main rotor was instrumented with 39 hub and blade strain gages, and six shaft strain gages. Descriptions of the instrumentation, the data acquisition and the data reduction procedures are published along with the data in ref. 14. Table 1 lists the basic SA349/2 aircraft characteristics. The six force and moment components at the hub were obtained from strain-gage measurements on the rotor shaft. Four of the six shaft strain gages measured the shaft bending moments, $m_{a}$ and $m_{b}$, at distances $l_{a}$ and $l_{b}$ below the rotor (fig. 1). The measurements of $m_{a}$ and $m_{b}$ were sufficient to derive the total in-plane rotating frame forces and moments at the hub $\left(f_{t x}, f_{t y}, m_{t x}, m_{t y}\right)$. This was possible since the $x$ - and y-components of the forces and moments, although $90 \mathrm{deg}$. out of phase, experienced the same loading conditions around the azimuth and thus were of equal magnitude. The in-plane rotating frame forces and moments at the hub were calculated assuming the shaft was a beam isolated from other external forces and moments. In deriving the rotating frame hub loads, then, the $x$-component was computed from the measured shaft loads, and the y-component was obtained by introducing a $90 \mathrm{deg}$. phase shift. The nonrotating frame forces and moments were derived as outlined in sections 3.1 and 3.2. The two remaining shaft gages measured rotor thrust and rotor torque, both of which are the same in the rotating and fixed frame.

\section{Analytical Approach}

Three topics related to the SA349/2 hub loads were studied using a comprehensive rotorcraft analysis. The first was a correlation of SA349/2 hub loads flight test data with predicted hub loads, to assess the effect of the wake model on the predictions. Second, variations in the hub forces resulting from alterations in the blade radial mass distribution and chordwise cg location were examined. Finally, the effect of using HHC to reduce predicted SA349/2 hub forces was investigated.The last two topics were theoretical investigations.

The SA349/2 hub loads were studied using a comprehensive analytical model of rotorcraft aerodynamics and dynamics (CAMRAD). CAMRAD (refs. 15-16) is an analysis used to examine a variety of two-rotor helicopter designs. For this study, predictions of the rotor hub forces were obtained by trimming the CAMRAD model of the SA349/2 to the aircraft forces and moments. Five blade bending modes; rigid flap and lag , and three coupled flap/lag elastic bending modes, and two elastic torsion modes were included in the rotor analysis. Control system stiffness, essentially a rigid torsion mode, was included as well. 
3.1 Derivation of Total Rotating and Nonrotating Frame Hub Forces and Moments.

The rotating and nonrotating frame hub forces and moments are shown in fig. 1 . The components $f_{t x}$ $f_{t y}, m_{t x}$, and $m_{t y}$ represent the combined in-plane forces and moments for all three blades in the rotating frame, shaft axis system $(x, y, z)$. As mentioned in section 2 , the in-plane rotating frame forces, $f_{t x}$ and $f_{t y}$, have equal amplitudes. The same is true for the in-plane moments $m_{t x}$ and $m_{t y}$. The components $F_{X}, F_{Y}, M_{X}$, and $M_{Y}$ are the corresponding in-plane loads in the nonrotating frame, shaft-axis system $(X, Y, Z) . F_{Z}\left(=f_{t Z}\right)$ and $M_{Z}\left(=m_{t Z}\right)$ are the out-of-plane loads in the nonrotating frame, shaft-axis system.

The total fixed-system hub forces were obtained from the total rotating hub forces, which in turn were derived from the blade root forces, as shown in fig. 2. Figure $2 a$ shows the single-blade hub force components, which are obtained by integrating the local forces along the blade. The three force components acting at the root of each blade are $f_{c}$, the hub-plane force in the chordwise direction, $f_{r}$, the hub-plane force in the radial direction, and $f_{n}$, the blade force normal to the hub-plane. Since these force components are functions of time, they can be represented for the $j^{\text {th }}$ blade as a sum of $i$ harmonics;

$$
\begin{aligned}
& f_{c}\left(\Psi_{j}\right)=\Sigma f_{c c i} \cos \left(i \Psi_{j}\right)+f_{c s i} \sin \left(i \Psi_{j}\right) \\
& f_{r}\left(\Psi_{j}\right)=\Sigma f_{r c i} \cos \left(i \Psi_{j}\right)+f_{r s i} \sin \left(i \Psi_{j}\right) \\
& f_{n}\left(\Psi_{j}\right)=\Sigma f_{n c i} \cos \left(i \Psi_{j}\right)+f_{n s i} \sin \left(i \Psi_{j}\right),
\end{aligned}
$$

where the subscripts 'ci' and 'si' refer to the amplitudes of the cosine and sine components of the $\mathrm{i}^{\text {th }}$ harmonic. Figure $2 \mathrm{~b}$ shows the force components for all three blades, where blade one is at $\Psi_{1}=0 \mathrm{deg}$ (aligned with the tail boom), blade two is at $\Psi_{2}=120 \mathrm{deg}$ and blade three is at $\Psi_{3}=240 \mathrm{deg}$. The total rotating frame hub force components in the $x, y, z$ axis system are then obtained by summing the singleblade components as follows;

$$
\begin{aligned}
& f_{t x}(\Psi)=f_{r}\left(\Psi_{1}\right)-f_{r}\left(\Psi_{1}+120\right) \sin 30-f_{r}\left(\Psi_{1}+240\right) \sin 30 \\
& -f_{c}\left(\Psi_{1}+120\right) \cos 30+f_{c}\left(\Psi_{1}+240\right) \cos 30 \\
& f_{\text {ty }}(\Psi)=-f_{C}\left(\Psi_{1}\right)+f_{C}\left(\Psi_{1}+120\right) \sin 30+f_{C}\left(\Psi_{1}+240\right) \sin 30 \\
& -\mathrm{f}_{\mathrm{r}}\left(\Psi_{1}+120\right) \cos 30+\mathrm{f}_{\mathrm{r}}\left(\Psi_{1}+240\right) \cos 30 \\
& f_{t z}(\Psi)=f_{n}\left(\Psi_{1}\right)+f_{n}\left(\Psi_{1}+120\right)+f_{n}\left(\Psi_{1}+240\right)
\end{aligned}
$$

Substituting eqs. 1 into eqs. 2 and transforming from the single-blade coordinate system $(c, r, n)$ to the total rotating frame coordinate system $(x, y, z)$ yields equations for $f_{t x}, f_{t y}$, and $f_{t z}$ in harmonic form (ref. 14). Interestingly, because of cancellations due to rotor symmetry and relative blade phase, only the $n b \pm 1$ harmonics of $f_{t x}$ and $f_{t y}$ are non-zero, and only the nb harmonics of $f_{t z}$ exist in the rotating frame. When transforming to the fixed system, the nb- 1 and $n b+1$ harmonics of the in-plane forces in the rotating frame combine to produce only $n b$ harmonics of $F_{X}$ and $F_{Y}$. These fixed system forces are obtained through the following coordinate transformation, pictured in fig. 2c;

$$
\begin{aligned}
& F_{X}(\Psi)=f_{t x} \cos (\Psi)+f_{t y} \sin (\Psi) \\
& F_{Y}(\Psi)=-f_{t x} \sin (\Psi)+f_{t y} \cos (\Psi) \\
& F_{Z}(\Psi)=f_{t z}(\Psi) .
\end{aligned}
$$

The results section presents correlations of the in-plane loads with forces and moments in both the rotating and nonrotating frames. Because the nb- 1 and $n b+1$ harmonics in the rotating frame combine to produce the $\mathrm{nb}$ harmonics in the fixed-frame, the relationship between the rotating and nonrotating frame forces is not straightforward. In addition, aircraft vibration is generated by the fixed frame forces but these forces originate in the rotating frame. Thus it is instructive to examine results in both the rotating and nonrotating frames. 
3.2 Derivation of Hub Force Aerodynamic and Inertial Components.

To determine the mechanisms through which the hub forces were altered by changes in blade mass distribution and blade cg location, the components of the single-blade forces, $\mathrm{fc}$, $\mathrm{fr}$, and $\mathrm{fn}$, which make up the total forces as shown in fig. 2, were examined. The single-blade in-plane forces can be decomposed into aerodynamic and inertial components using the following relationships (ref. 17, pp. 64, 100-102),

and

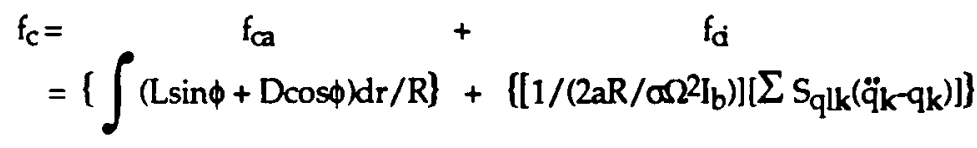

$$
\begin{aligned}
& \mathrm{f}_{\mathrm{r}}=\quad \mathrm{f}_{\mathrm{ra}}+\mathrm{f}_{\mathrm{ni}} \\
& =\left[\int\left[D u_{r} / U-\Sigma q_{k}\left(\eta_{f k} f_{n a}-\eta_{l k} f_{c a}\right)\right] d r / R\right\}+\left\{\left[1 /\left(2 a R / \sigma \Omega^{2} I_{b}\right)\right]\left(\Sigma 2 S_{q_{l k} \dot{q}_{k}}\right)\right\}
\end{aligned}
$$

where $f_{c a}$ and $f_{r a}$ are the aerodynamic components of $f_{c}$ and $f_{r}$, and $f_{c i}$ and $f_{r i}$ are the inertial components. The aerodynamic chordwise force, $\mathrm{f}_{\mathrm{ca}}$, is a function of the c-components of blade lift $(\mathrm{L})$ and drag (D); fra is a function of blade drag, the r-component of the local blade velocity ( $u_{r} / U$ ), the modal displacements ( $q_{k} \eta_{f k}$ and $q_{k} \eta_{l k}$ where $q_{k}$ are the nondimensional blade degrees of freedom, $\eta_{\mathrm{fk}}$ and $\eta_{\mathrm{lk}}$ are the flap and lag components of the bending mode shapes), and the $\mathrm{c}$-and $\mathrm{n}$-components of the singleblade aerodynamic forces $\left(f_{\mathrm{ca}}\right.$ and $\left.f_{n a}\right)$. The components $f_{\mathrm{ci}}$ and $f_{r i}$ are, neglecting hub and shaft motion, simply functions of blade lag inertial constants, $S_{q l k}$ and nondimensionalized blade bending degrees of freedom, $q_{k}$. The subscript $k$ refers to the bending modal component. The individual inertial and aerodynamic contributions to $f_{t x}$ are then obtained by combining eqs. 4 and 5 according to the relationship given in eq. 2 .

The 3/rev out-of-plane forces can be similarly broken down into aerodynamic and inertial components using the equation (ref. 17, pp. 65, 100),

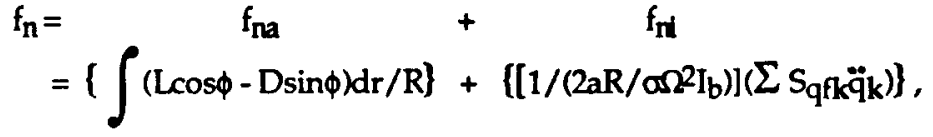

where $f_{n a}$, the acrodynamic component of $f_{n}$, is a function of the components of lift and drag; and $f_{n i}$, the inertial component of $f_{n}$, is a function of the blade flap inertial constants, $S_{q f k}$, and the nondimensionalized blade degrees of freedom, $q_{k}$. The total out-of-plane forces for the inertial and aerodynamic components are then derived according to the relationship in eq. 2 for $f_{t z}$.

The inertial components of the forces, $f_{c i}, f_{r i}$, and $f_{n i}$, are comprised of the inertial constants and the nondimensionalized blade degrees of freedom. The inertial constants are given by (ref. 17, p. 69)

$$
\mathrm{S}_{\mathrm{qlk}}=\left(1 / \mathrm{I}_{\mathrm{b}}\right) \int \eta_{\mathrm{lk}} \mathrm{mdr} \text { and } \mathrm{S}_{\mathrm{qfk}}=\left(1 / \mathrm{I}_{\mathrm{b}}\right) \quad \eta_{\mathrm{fk}} \mathrm{mdr}
$$

where $I_{b}$ is the characteristic blade moment of inertia, $\eta_{\mathrm{k}}$ and $\eta_{\mathrm{fk}}$ are the lag and flap components of the bending mode shapes, and $\mathrm{m}$ is the sectional blade mass. The nondimensional blade degrees of freedom are derived from the following coupled flap/lag equation of motion (ref. 17, p 62),

$$
\begin{aligned}
& \mathrm{I}_{\mathbf{q} k}\left(\ddot{\mathrm{q}}_{\mathbf{k}}+\mathrm{g}_{\mathbf{s}} v_{\mathbf{k}} \dot{q}_{\mathbf{k}}+v_{\mathbf{k}}{ }^{2} \mathrm{q}_{\mathbf{k}}\right)+(\text { nonlinear terms, torsion coupling,...) } \\
& =\gamma(1 / \mathrm{ac}) \mathrm{M}_{\mathrm{qk}(\mathrm{aero})}+\text { constant, }
\end{aligned}
$$

where $I_{q k}=\left(1 / I_{b}\right) \int \eta_{k}{ }^{2} m d r / R$ is the blade modal inertia. Thus the nondimensionalized blade degrees of freedom are functions of bending modal frequencies, $v_{k}$ modal inertias, $\mathrm{I}_{\mathrm{q}} \mathrm{k}$ and aerodynamic forcing

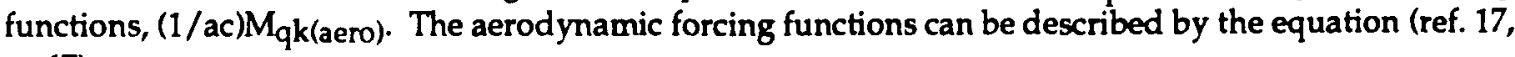
p. 67),

$$
(1 / \mathrm{ac}) \mathrm{M}_{\mathrm{qk}(\mathrm{acro})}=\int(1 / \mathrm{ac})\left(\eta_{\mathrm{fk}} \mathrm{f}_{\mathrm{na}}-\eta_{\mathrm{l} k \mathrm{f}} \mathrm{f}_{\mathrm{ca}}\right) \mathrm{dr} .
$$

The inertial components of eqs. 4-6 suggest that any changes in the inertial hub forces caused by altering the blade properties will arise through changes in the bending modal characteristics $\left(\mathbf{v}_{\mathbf{k}}, \mathrm{I}_{\mathbf{q}} \mathbf{k}\right.$, $\left.\eta_{\mathrm{fk}}, \eta_{\mathrm{lk}}\right)$ and/or the aerodynamic forcing function $\left((1 / \mathrm{ac}) \mathrm{M}_{\mathrm{qk}}(\mathrm{aero})\right)$. The blade bending modal response depends partly on the blade mass distribution, so altering the blade mass distribution is expected to 
affect the hub loads through changes in the bending modal response. In contrast, eq. 9 indicates that the aerodynamic forcing function depends not only on the bending modal characteristics, but also on the blade lift through $\mathrm{f}_{\mathrm{na}}$ and $\mathrm{f}_{\mathrm{ca}}$. Likewise, the aerodynamic components of eqs. 4-6 are all influenced by the blade lift. The lift is a function of the blade angle of attack, $\alpha$, which depends on the blade pitch (both rigid and elastic) and the local blade velocity (ref. 12). Changes in the aerodynamic components of the hub forces caused by altering the blade properties can be traced to changes in the elastic component of blade pitch, $\theta_{\mathbf{e}}$. The elastic blade pitch is a function of the elastic torsion modal response of the blade. Since the chordwise cg location affects this dynamic torsion response, shifting the cg location is expected to affect the hub loads through changes in the blade angle of attack. Section 4.2 explores these speculations.

\subsection{Higher Harmonic Control Algorithm}

The effectiveness of using HHC to reduce the SA349/2 hub loads was investigated with CAMRAD/JA, a modified version of CAMRAD developed at Johnson Aeronautics. The objective was to use $3 / \mathrm{rev}$ swashplate control to minimize the $3 / \mathrm{rev}$ hub shears. The measurement vector was given by,

$$
z=\left[\left(C_{F X} / \sigma\right)_{3 c}\left(C_{F X} / \sigma\right)_{3 s}\left(C_{F Y} / \sigma\right)_{3 c}\left(C_{F Y} / \sigma\right)_{3 s}\left(C_{F Z} / \sigma\right)_{3 c}\left(C_{F Z} / \sigma\right)_{3 s}\right]
$$

where $\mathrm{C}_{\mathrm{FX}}, \mathrm{C}_{\mathrm{FY}}$, and $\mathrm{C}_{\mathrm{FZ}}$ are the nonrotating frame hub force coefficients relative to the shaft axes, $\sigma$ is the rotor solidity, and the subscripts ' $3 c$ ' and ' $3 s$ ' refer to the $3 / \mathrm{rev}$ cosine and sine components. The control vector was given by,

$$
\theta_{\text {con }}=\left[\left(\theta_{0}\right)_{3 c}\left(\theta_{0}\right)_{3 s}\left(\theta_{c}\right)_{3 c}\left(\theta_{c}\right)_{3 s}\left(\theta_{s}\right)_{3 c}\left(\theta_{s}\right)_{3 s}\right],
$$

where $\theta_{0}, \theta_{c}$, and $\theta_{s}$ are the nonrotating frame collective, lateral cyclic and longitudinal cyclic pitch controls.

A controller was introduced between the trim and circulation/motion iteration sections of the solution procedure. The controller was similar to the self-tuning regulators used for HHC of helicopters (refs. 18 and 19). However, instead of applying the HHC algorithm to a dynamic system (as would be the case in flight), a Newton-Raphson algorithm was applied to the aircraft at a specified operating condition. As a result, the controller became just an algorithm to find the optimum solution to a nonlinear algebraic problem.

The controller uses the quadratic performance function,

$$
J=z^{T} z+0.0002 \Delta \theta_{\text {con }}{ }^{T} \Delta \theta_{\text {con }},
$$

where $\Delta \theta_{\text {con }}$, the change in controls from one iteration to the next, was introduced to improve convergence. A locally linearized model of the helicopter, $\Delta z=T \Delta \theta_{\operatorname{con}}$, was assumed (ref. 18). $T$ was the transfer-function matrix. Minimizing the dimensionless performance function, J, led to the linear feedback equation $\Delta \theta_{\text {con }}=-C z$, where $C$ was the controller gain. Convergence of the controller was defined in terms of the difference between successive iterations of $\mathrm{J}$, where $\Delta \mathrm{J}<1.0 \mathrm{E}-8$ indicated convergence. At the beginning of each Newton-Raphson trim iteration (using new values for the primary controls), the transfer-function matrix was identified by successive, prescribed perturbations of the higher harmonic controls. During the controller iterations the matrix $T$ was then recursively updated using an exponential filter, which weighted more heavily the most recent events (ref. 18).

\section{Results}

4.1 Hub Loads Correlations

4.1.1 Rotor Performance and Trim Conditions

All predictions of the rotor trim conditions and the hub loads shown in this section were obtained by trimming the CAMRAD model of the SA349/2 using the aircraft forces and moments (ref. 9). The correlation results are presented for four level-flight conditions ranging in advance ratio from 0.14 to 0.37 . Flight parameters for the four conditions are listed in table 2. Figure 3 shows the difference between predicted and measured rotor trim angles, plotted as a function of advance ratio. Figure 3a indicates that the $1 / \mathrm{rev}$ longitudinal flapping angle, $\beta_{1 c}$, is predicted to within $1 / 2 \mathrm{deg}$; however, the shaft angle, and as a result the tip-path-plane angle $\left(\alpha_{\mathrm{s}}-\beta_{1 \mathrm{c}}\right)$, are both in error by approximately 2 deg. CAMRAD's prediction is nose up with respect to the measured data. Figure $3 b$ shows the difference between predicted and measured rotor blade pitch trim parameters. In general, the collective and longitudinal cyclic pitch angles are overpredicted by an average of $1 \mathrm{deg}$. Lateral cyclic pitch is 
overpredicted by $1 / 2 \mathrm{deg}$. The rotor blade trim data were obtained from the measured stick positions. These measurements may not be very accurate, however, because of flexibility in the linkages between the rotor blades and the control sticks.

\subsubsection{Effect of the Rotor Wake Model on Hub Loads Correlations}

Correlations of the hub forces and moments in the shaft axis system were performed for the four flight conditions listed in table 2. The results, plotted as a function of advance ratio, are shown for both the rotating and nonrotating reference frames. The measured data are compared with predictions made using both a uniform inflow and a nonuniform inflow (prescribed wake) wake model.

The hub force correlation, shown in figs. 4-6, was performed for the $x$-component of the total rotating in-plane force, $f_{1 X}$, the total resolved forces in the nonrotating frame, $F_{X}$ and $F_{Y}$, and the total nonrotating frame out-of-plane force, $F_{Z}$. Figure 4 shows $f_{t \times} 1 /$ rev as a function of advance ratio, and the corresponding mean FX and FY components. An estimate of the SA349/2 hub drag and the Xcomponent of the rotor weight were subtracted from $F_{X \text { (meas) and }} f_{t x \text { (meas) }}$ for each condition, to be consistent with the predictions. The estimates, which are listed in table 2 , were derived from,

$$
F_{X}=F_{X(\text { meas })}+m_{h} g \sin \alpha_{s}-0.5 f_{h} \rho\left(V_{0} \cos \alpha_{s}\right)^{2} \text {, }
$$

where $f_{h}=0.2 \mathrm{~m}^{2}$ is the estimated $\mathrm{D} / \mathrm{q}$ for the hub, $\mathrm{m}_{\mathrm{h}}$ is the mass of the rotor hub, $\alpha_{8}$ is the shaft angle and $V_{0}$ the helicopter velocity. Figure $4 a$ shows that the in-plane rotating frame force decreased with advance ratio up to $\mu=0.35$. In the nonrotating frame, fig. $4 \mathrm{~b}$ shows that $F_{X}$ also decreased with advance ratio, indicating that the lift vector became increasingly aligned with the aircraft cg. At low speed ( $\mu=0.14$ ), where computed propulsive force was approximately $500 \mathrm{~N}$, FX contributed significantly to aircraft propulsion. At high speed $(\mu=0.37)$, however, the computed propulsive force increased to $3500 \mathrm{~N}$, while $\mathrm{F}_{X}$ went to zero. Hence $\mathrm{FX}_{X}$ was not a significant factor at high speed. FY, on the other hand, increased with advance ratio, reflecting an increase in tail rotor thrust required to balance the rotor torque. The correlation of $1 / \mathrm{rev} \mathrm{f}_{\mathrm{tx}}$ (fig. $4 \mathrm{a}$ ) revealed a constant $200 \mathrm{~N}$ offset between the theory and the data. In the nonrotating frame, this offset was manifested in mean FX at low speed and in mean FY at high speed. The shift in offset from one fixed-frame force component to the other indicates a shift in the phase of $f_{t x}$. Using a nonuniform inflow wake model offered no clear improvement to the correlation of steady drag and side force, because the trim state of the helicopter was the same for both wake models for the full advance ratio sweep.

Figure 5 shows the $f_{t \times} 2 /$ rev and $4 /$ rev rotating frame forces, and the corresponding $3 /$ rev nonrotating frame components of $F_{X}$ and $F_{Y}$. The $f_{t X} 2 /$ rev was the most significant contribution to the $3 / \mathrm{rev}$ fixed-frame loads, increasing with advance ratio. In the nonrotating frame, the magnitude of $F_{X}$ $3 / \mathrm{rev}$ (predicted) was approximately $30 \%$ of the propulsive force magnitude. Both $\mathrm{FX}_{X} 3 / \mathrm{rev}$ and $\mathrm{FY}_{Y}$ $3 / \mathrm{rev}$ exhibited the same trend of increasing with advance ratio. The correlation of oscillatory forces improved significantly with the use of a nonuniform inflow wake model. However, even using this wake model, the accuracy of the oscillatory force predictions generally deteriorated with increasing velocity.

The prediction of $3 / \mathrm{rev} \mathrm{F}_{Z}$ is shown in fig. 6. The mean rotor thrust is not shown, since it was not accurately measured. The $3 / \mathrm{rev} \mathrm{F}_{Z} 3 / \mathrm{rev}$ correlation exhibited a significant improvement with the use of a nonuniform inflow wake model, although the measured force increased more rapidly with advance ratio than the predicted force. Comparing fig. $6 \mathrm{~b}$ with fig. $5 \mathrm{~b}$ reveals that the amplitude of $3 / \mathrm{rev} \mathrm{F}_{Z}$ was significantly greater than the amplitudes of the $3 /$ rev in-plane forces, $F_{X}$ and $F_{Y}$.

The hub moment correlation, shown in figs. 7-9, was performed for the total rotating in-plane moment, $m_{t x}$, the corresponding resolved components in the nonrotating frame, $M_{X}$ and $M_{Y}$, and the total nonrotating frame out-of-plane moment, $\mathrm{MZ}$. Figure 7 shows the total $\mathrm{m}_{\mathrm{tx}} 1 / \mathrm{rev}$ as a function of advance ratio, and the corresponding mean $M_{X}$ and $M_{Y}$ components. As with $f_{t x} 1 / \mathrm{rev}, m_{t x} 1 /$ rev decreases with advance ratio, again suggesting that the lift vector and aircraft $\mathrm{cg}$ were aligning as the velocity increased. The trends of the fixed-frame mean moments were similar to the trends of the mean forces; the pitching moment $\left(M_{Y}\right)$ decreased, and the roll moment $\left(M_{X}\right)$ increased with advance ratio. In both the rotating and nonrotating frame, the trend of the data was well predicted by CAMRAD. The correlation of $1 / \mathrm{rev} \mathrm{m}_{\mathrm{tx}}$ (fig. $7 \mathrm{a}$ ) improved with increasing advance ratio. In the nonrotating frame, the prediction of $\mathrm{MX}$ was very good. Most of the rotating frame error was manifested in MY. Using a nonuniform inflow wake model offered no clear improvement to the correlation in fig. 7 , again reflecting that trim is independent of the wake model. 
Figure 8a shows the $m_{\mathrm{tx}} 2 / \mathrm{rev}$ and $4 / \mathrm{rev}$ rotating frame moments; the corresponding $3 / \mathrm{rev}$ nonrotating frame components of $M_{X}$ and $M_{Y}$ are shown in fig. $8 b$. As with the hub forces, the $m_{t x} 2 / r e v$ is the most significant contribution to the $3 / \mathrm{rev}$ moments, and all components increase with advance ratio. In the fixed-frame, the magnitudes of the measured $3 / \mathrm{rev} \mathrm{MX}_{X}$ and $\mathrm{M}_{Y}$ are nearly identical, although the predicted $\mathrm{MX}_{X}$ is higher than $\mathrm{MY}_{\mathbf{Y}}$. The correlation improved significantly with the introduction of a nonuniform inflow wake model, which reduced the error by a factor of two or more for 3/rev MY.

The prediction of $M_{Z}$ is shown in fig. 9. The rotor torque, $M_{Z}$ (fig. 9a), was well predicted for all advance ratios, indicating a close match with rotor power as well. The prediction was within $7 \%$ using a uniform inflow wake model, however, using a nonuniform inflow wake model increased the correlation to within $1 \%$. As expected, the mean torque increased with advance ratio. Figure $9 \mathrm{~b}$ shows that the $\mathrm{Mz} 3 / \mathrm{rev}$ correlation exhibited significant improvement with the use of a nonuniform inflow wake model, particularly at the higher advance ratios.

\subsection{Effect on the Hub Loads of Changing the Blade Mass Distribution and Chordwise cg Location}

An examination of the influence of changes in the blade cg location and blade mass distribution on the hub loads was performed, in an effort to better understand the relationship between specific blade parameters and the subsequent forces and moments at the rotor hub. The highest speed condition, V3106 $\left(\mu=0.37, C_{T} / \sigma=0.066\right)$, was chosen for this investigation. Figures 4-9 showed that the hub loads were generally largest for this condition. All predictions were made using a nonuniform inflow, prescribed wake model.

Two changes in the blade mass distribution were studied, as shown in fig. 10. First, the blade mass was decreased $30 \%$ from $0-64 \%$ radial station, and increased $30 \%$ from $64-100 \%$ radial station, yielding a $12 \%$ net decrease in the total blade mass (MASS OUTBOARD). Second, the blade mass was increased $30 \%$ from $0-64 \%$ radial station, and decreased $30 \%$ from $64-100 \%$ radial station, yielding a $12 \%$ net increase in the total blade mass (MASS INBOARD).

Two changes in the cg location were also studied. The chordwise blade cg location was shifted forward $0.5 \%$ (CG FORWARD) and aft 2.0\% (CG AFT) from the nominal 24.7\% chord position. The forward position corresponded to the furthest forward position at which the analysis would converge. The aft position corresponded to the aft blade cg location flight tested by the SA349/2 helicopter (ref. 14 ) in the second flight test.

\subsubsection{Overall Effect of Blade Structural Changes in the Hub Loads}

The overall effects of the changes in blade mass distribution and $\mathrm{cg}$ location on the amplitudes of the $3 / \mathrm{rev}$ forces and moments are shown in fig. 11 . Moving the mass outboard decreased all the $3 / \mathrm{rev}$ loads. Moving the mass inboard increased the in-plane and decreased the out-of-plane forces and moments. Shifting the blade $\mathrm{cg}$ location from forward to aft increased the in-plane, and decreased the out-of-plane loads. Interestingly, the effect of the blade parameter changes was similar in trend for both the forces and moments, suggesting that the physical mechanisms for these changes were the same for both types of loads. Hence, the subsequent investigation of the effect on the hub loads of altering the blade properties focused on the hub forces only.

\subsubsection{Procedure for Investigating the Effect of Blade Parametric Changes in the Hub Loads}

Determining how and why alterations in the blade mass distribution and chordwise $\mathrm{cg}$ location affected the hub forces was accomplished by,

1. Separating $f_{t x}$ and $f_{t z}$ into aerodynamic and inertial terms

2. Examining the inertial terms for an individual blade to

a. determine which bending modal components were affected by the changes in blade properties

b. determine which inertial terms were responsible for the changes in modal components

c. identify the sources of change; either through the modal characteristics

$\left(v_{k}, \eta_{k}, I_{q k}\right)$ or through the aerodynamic forcing function (1/ac) $\left(\mathrm{M}_{\mathrm{qk}(\mathrm{aero})}\right)$

3. Examining the aerodynamic terms for an individual blade to

a. determine how single-blade hub force components $\left(f_{\mathrm{ca}}, f_{\mathrm{ra}}, f_{\text {na }}\right)$ were affected

b. determine the sources of change in $\mathrm{f}_{\mathrm{ra}}$, through bending modal components

c. determine the sources of change in $f_{c a}$ and $f_{n a}$, through blade lift 
Following the above process, the next three sections investigate the effect of changes in the blade mass distribution and chordwise cg location on the hub forces.

\subsubsection{Aerodynamic and Inertial Components of $f_{t x}$ and $f_{t z}$}

To better understand how the blade alterations caused changes in the hub loads, the total rotating frame forces were first separated into inertial and aerodynamic components. The $3 / \mathrm{rev}$ in-plane nonrotating frame forces were derived from the $2 / \mathrm{rev}$ and $4 / \mathrm{rev}$ rotating frame forces. However, fig. 5 showed that the predicted $4 / \mathrm{rev}$ contribution was much smaller than the predicted $2 / \mathrm{rev}$ contribution for the flight condition under investigation. Therefore, examining the effect of the blade parameter changes on the $2 / \mathrm{rev}$ rotating frame force was sufficient for determining the overall effect on the $3 / \mathrm{rev}$ nonrotating frame force. In addition, since the magnitudes of both $f_{t x}$ and $f_{t y}$ are equal, examining only $f_{t x}$ in the rotating frame was sufficient. The inertial and aerodynamic components of the $3 / \mathrm{rev}$ out-ofplane force, $f_{t z}$, were examined as well.

Figure 12 presents vector plots of the total rotating frame $2 / \mathrm{rev} \mathrm{f}_{\mathrm{tx}}$ hub force, separated into aerodynamic and inertial components. The effect of changing the blade mass distribution on the inplane $2 / \mathrm{rev}$ force is shown in fig. 12a. The total vectors (T) are plotted for the baseline, the MASS OUTBOARD, and the MASS INBOARD cases, and each total vector has corresponding inertial (I) and aerodynamic (A) components. Figure 12a shows that the magnitude of the aerodynamic vector is relatively insensitive to changes in the blade mass distribution. However, the phase of the aerodynamic component, and both the magnitude and phase of the inertial vector change (particularly for the mass inboard case). The increase of $2 / \mathrm{rev} f_{\mathrm{fx}}$ as the blade mass distribution shifts from outboard to inboard, and total blade mass increases $24 \%$, is due primarily to changes in the inertial forces. The effect of shifting the blade chordwise cg location on the in-plane $2 / \mathrm{rev}$ force is shown in fig. $12 \mathrm{~b}$. Shifting the cg location from forward to aft results in a proportional increase of both the inertial and aerodynamic vectors, with no associated phase shift.

Figure 13 shows the breakdown of the out-of-plane $3 / \mathrm{rev}$ force into inertial and aerodynamic components. The effect of changes in the blade mass distribution is plotted in fig. 13a, where evidently most of the change in the total vector resulted from changes in the inertial component. Interestingly, the magnitude of the inertial vector decreased for both the MASS INBOARD and MASS OUTBOARD cases, causing the total vectors to decrease compared to the baseline. The effect of shifting the chord wise $\mathrm{cg}$ location is more straightforward, as shown in fig. 13b. The out-of-plane inertial and aerodynamic components both increased as the blade $\mathrm{cg}$ shifted from forward to aft. However, because the phase changed, the amplitude of the total vector decreased.

Although the breakdown of hub forces into aerodynamic and inertial components reveals that altering the blade mass distribution affects primarily the inertial loads, while shifting the cg location influences both the aerodynamic and inertial components, the question of how these changes influence the aerodynamic and inertial forces has not been answered. Further examination of the aerodynamic and inertial components is required. A schematic of the rotating frame hub forces, representing the relationships between the single-blade forces $\left(f_{c}, f_{r}\right.$, and $\left.f_{n}\right)$ and the total rotating frame forces $\left(f_{t x}\right.$ and $f_{t z}$, is shown in fig. 14. The schematic begins with the total rotating frame forces, $f_{t x}$ and $f_{t z}$, splits them into their respective inertial and aerodynamic components (as already discussed), then shows the corresponding aerodynamic and inertial terms of the single-blade forces $\left(f_{\mathrm{cl}}, \mathrm{f}_{\mathrm{ca}}, \mathrm{f}_{\mathrm{rl}}, \mathrm{f}_{\mathrm{ra}}, \mathrm{f}_{\mathrm{ni}}, \mathrm{f}_{\mathrm{na}}\right)$ as given in eqs. 4-6. The solid lines in fig. 14 lead to terms which are significantly affected by the blade structural changes under investigation. The other terms are either negligible contributions to the total, or unaffected by the changes in blade properties. The inertial terms can be decomposed into bending modal components. The aerodynamic terms are functions of $\alpha$, which depends on torsion modal components. The aerodynamic term $f_{r a}$, however, is a function of both $\alpha$ and the bending modes.

\subsubsection{Decomposing the Inertial Components}

The inertial terms of $f_{t x}$ and $f_{t z}$ were examined first. As shown by the expressions for the radial and chord wise inertial forces, $f_{r}$ and $f_{c l}$, in fig. 14, the total inertial in-plane force, $f_{|x|}$, can be written as a sum of the modal components of $f_{r l}$ and $f_{c i}$. Likewise the total inertial out-of-plane force, $f_{\mathrm{tzl}}$, can be represented by the modal components of the single-blade inertial force, $f_{n 1}$. The significant modal components contributing to $2 / \mathrm{rev} f_{t x i}$ and $3 / \mathrm{rev} f_{|z|}$ are shown in fig. 15 . The total inertial force for each case is labeled "I" to be consistent with fig. 12. Figure 15a indicates first of all that only the first three bending modes, rigid flap, rigid lag and first elastic bending, were significant to the total $2 / \mathrm{rev}$ in-plane inertial force. Changes in the $2 / \mathrm{rev}$ in-plane inertial force, $f_{|x|}$, caused by altering the blade mass distribution were manifested primarily through changes in the lag component of the first elastic bending modal contribution ( $k=3$ ). Recall that since coupled bending modes are used in the CAMRAD 
analysis, each elastic bending mode has both a flap and a lag deflection component. Changes caused by shifting the $\mathrm{cg}$ location were manifested through changes in the rigid lag bending contribution $(\mathbf{k}=1)$. The out-of-plane inertial force, $3 / \mathrm{rev} f_{t z 1}$, was virtually independent of the rigid lag bending mode $(k=1)$. Figure $15 b$ indicates that only the rigid flap and first elastic bending modal components contributed significantly to the $3 / \mathrm{rev}$ out-of-plane inertial force (I). The changes in $3 / \mathrm{rev} \mathfrak{f}_{t z i}$ arising from changes in the blade mass distribution were manifested primarily through the flap component of the first elastic bending modal contribution $(k=3)$, demonstrated in fig. $15 \mathrm{~b}$. Shifting the $c g$ location, however, affected both the rigid flap $(k=2)$ and first elastic bending $(k=3)$ mode contributions to $3 / \mathrm{rev}$ $\mathrm{f}_{\mathrm{tzi}}$. Table 3 , which lists the blade bending modal frequencies for the five cases, reveals that changing the blade mass distribution affected the bending modal frequencies, while shifting the $\mathrm{cg}$ location did not. The torsion modal frequencies were unaffected for all cases.

The next step was to answer the following two questions: 1) why does changing the blade mass distribution affect the first elastic coupled bending mode contribution to the $2 / \mathrm{rev}$ in-plane inertial force and the $3 / \mathrm{rev}$ out-of-plane inertial force, and 2) why does shifting the blade cg location affect the rigid lag contribution to the $2 / \mathrm{rev}$ in-plane inertial force and the rigid flap and first elastic bending mode contributions to $3 /$ rev out-of-plane inertial force? Figure 16 shows a flowchart of all terms contributing to $f_{t x i}$ and $f_{t z l}$. The inertial loads are a product of the modal response, $q_{k}$ and the blade inertial constants, $S_{\mathrm{q} l k}$ and $S_{\mathrm{qfk}}$. The significant modal components discussed in fig. 15 are further decomposed in the flowchart of fig. 16. As fig. 16 indicates, the inertial constants, $S_{q l k}$ and $S_{q f k}$ depend on the mode shapes, $\eta_{l k}$ and $\eta_{\mathrm{fk}}$, while the blade modal degrees of freedom, $q_{k}$, are functions of the blade modal frequencies, $v_{\mathbf{k}}$, the blade modal inertias, $\mathrm{I}_{\mathbf{q}}$, and the aerodynamic forcing function,

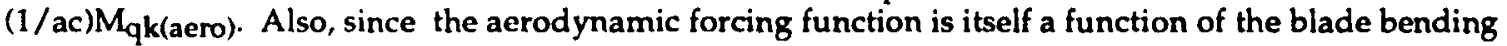
mode shapes, $\eta_{k}$, and $\eta_{f k}$, and the single-blade aerodynamic forces, $f_{\mathrm{Ca}}$ and $f_{\mathrm{na}}$, then the blade modal degrees of freedom are a function of these terms as well. Thus the fundamental elements of the inertial forces are either modal inertial components: $v_{k}, \eta_{l k}, \eta_{f k}$, and $I_{q k}$ or aerodynamic components: $f_{c a}$ and $f_{n a}$. (The aerodynamic components are decomposed in section 5.2.5.) The changes noted in the modal components of the inertial forces shown in figs. $15 a$ and $b$ were then traced to the modal inertial or aerodynamic elements.

Beginning with the effect of changes in blade mass distribution on the in-plane inertial force, $f_{t x i}$, we examined the terms of the $2 / \mathrm{rev}$ first elastic bending modal component (labeled in fig. 16). The blade lag inertia, $S_{q l k}$ a function of the blade mass and the lag component of the bending mode shape, $\eta$ lk, were affected by changes in the blade mass distribution. Figure 17a shows that the curvature of the lag component of the first elastic bending mode shape, $\eta_{13}$, increased slightly as mass shifted outboard and decreased slightly when mass moved inboard. The $2 / \mathrm{rev}$ blade bending degrees of freedom, qk, plotted in fig. $17 \mathrm{~b}$ for the first elastic bending mode, show the effect of each blade structural change on the first elastic bending degree of freedom, q3. Figure $17 \mathrm{~b}$ reveals that $q_{3}$ was particularly sensitive to the blade mass distribution. The first elastic bending component of the aerodynamic forcing function,

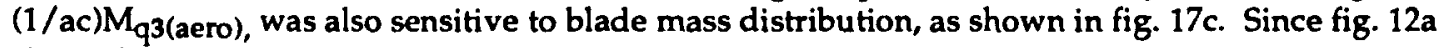
showed that the aerodynamic force was not significantly affected by altering the blade mass distribution, then the effect on the first elastic bending component of the aerodynamic forcing function,

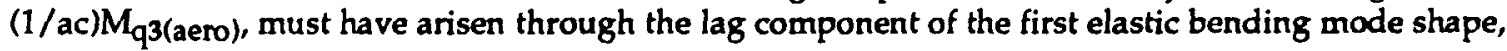
$\eta_{13}$. Examining the other terms influencing the first elastic bending degree of freedom, the modal frequency, $v_{3}$, and modal inertia, $\mathrm{I}_{\mathrm{q} 3}$, we see in tables 3 and 4 that $\mathrm{v}_{3}$ and $\mathrm{I}_{\mathrm{q} 3}$ also changed as the blade mass distribution shifted. Thus changes in the $2 / \mathrm{rev}$ in-plane inertial force, $f_{t x}$, resulting from changing the blade mass distribution, were caused by the first elastic bending modal elements: $v_{3}, I_{q 3}$ and $\eta_{13}$.

The effect on the out-of-plane loads of changing the blade mass distribution was manifested in the same way, except through $\mathrm{S}_{\mathrm{qf}}, \eta_{\mathrm{f3}}$ and the $3 / \mathrm{rev}$ component of $\mathrm{q}_{3}$, as indicated in fig. 16. Figure $18 \mathrm{a}$ shows that the flap component of the first elastic bending mode shape, $\eta_{\mathrm{f3}}$, was sensitive to changes in the blade mass distribution. This component was also of much larger amplitude than the lag component shown in fig. 17a; therefore, this bending mode is more of a flap mode than a lag mode. Figure $18 b$ reveals that changes in mass distribution affect the first elastic bending degree of freedom, q3, the most. Figure $18 \mathrm{c}$ shows that the first elastic bending component of the $3 /$ rev aerodynamic forcing function,

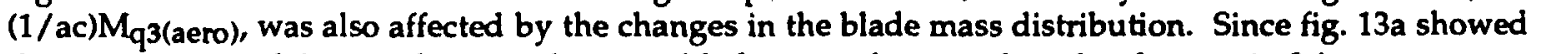
the insensitivity of the aerodynamic forces to blade mass changes, then the changes in $3 / \mathrm{rev}$ $(1 / \mathrm{ac}) \mathrm{M}_{\mathrm{q} 3(\mathrm{aero})}$ must have arisen through the flap component of the first elastic bending mode shape, 
$\eta_{f 3}$. As with the $2 / \mathrm{rev}$ in-plane inertial force, the $3 / \mathrm{rev}$ out-of-plane inertial force was affected by changes in the blade mass distribution through the first elastic bending modal elements: $v_{3}, L_{q 3}$ and $\eta_{f 3}$

A similar method was used to track down the significant effects on the in-plane $2 /$ rev inertial force, $\mathrm{f}_{\mathrm{txi}}$ due to shifting the $\mathrm{cg}$ location. Figure $15 \mathrm{a}$ has already shown that most changes in the inplane $2 /$ rev inertial force arose from changes in the rigid lag modal component. A review of tables 3 and 4 shows that the rigid lag modal frequency, $v_{1}$, and modal inertia, $\mathrm{I}_{\mathrm{q} 1}$, were not sensitive to blade $\mathrm{cg}$ location. The rigid lag mode shape, $\eta_{l 1}$, was also essentially unchanged. Hence the effect on the rigid lag component arose through the lag component of the $2 /$ rev aerodynamic forcing function,

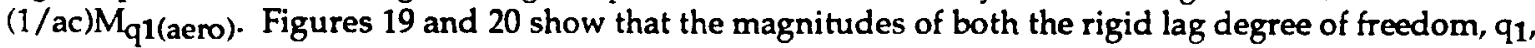

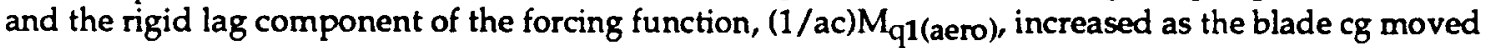
from forward to aft of the baseline position. This corresponds to the increase in the rigid lag component of $2 / \mathrm{rev} \mathrm{f}_{\mathrm{txi}}$ seen in fig. $15 \mathrm{a}$. The effect of shifting cg location on the $2 / \mathrm{rev}$ in-plane inertial force was manifested through the aerodynamic terms of the forcing function, $2 / \mathrm{rev} \mathrm{f}_{\mathrm{ca}}$ and $2 / \mathrm{rev} \mathrm{f}_{\text {na }}$.

The effect on the out-of-plane $3 / \mathrm{rev}$ inertial force, $\mathrm{f}_{\mathrm{tzi}}$, caused by shifting the $\mathrm{cg}$ location was also manifested through the aerodynamic forcing functions, $(1 / \mathrm{ac}) \mathrm{M}_{\mathrm{qk}}$ (aero). Figure $15 \mathrm{~b}$ showed, however, that the rigid flap $(k=2)$ and first elastic coupled bending $(k=3)$ modal components of $f_{t z i}$ were primarily affected (unlike $f_{t x i}$, where only the rigid lag mode was altered). The effects on the rigid flap component of both the rigid flap degree of freedom, $q_{2}$, and the rigid flap component of the

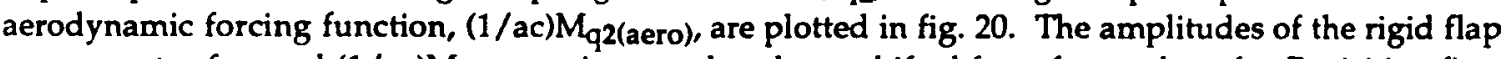

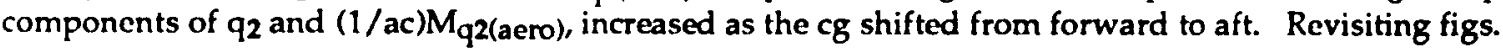
$18 \mathrm{~b}$ and $\mathrm{c}$ reveals that shifting the $\mathrm{cg}$ location had the opposite effect on the first elastic bending degree of freedom, $q_{3}$, and the first elastic bending component of the aerodynamic forcing function,

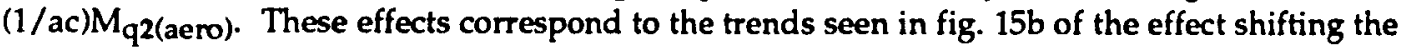
chordwise $\mathrm{cg}$ location had on the the rigid flap and first elastic bending modal components. The effect of shifting the $\mathrm{cg}$ location on $3 / \mathrm{rev} \mathrm{f}_{\mathrm{tzi}}$ was manifested through the aerodynamic forces of of the forcing function, $3 / \mathrm{rev} \mathrm{f}_{\mathrm{ca}}$ and $3 / \mathrm{rev} \mathrm{f}_{\text {na. }}$. The sources of change in these aerodynamic components are discussed in the next section.

\subsubsection{Decomposing the Aerodynamic Components}

The aerodynamic terms were examined in a manner similar to the inertial terms. The $2 / \mathrm{rev}$ inplane aerodynamic force, $f_{t x a}$, shown in fig. 12 , was separated into its chordwise and radial singleblade aerodynamic force components, $f_{\mathrm{ca}}$ and $\mathrm{f}_{\mathrm{ra}}$. In addition, $\mathrm{f}_{\mathrm{ra}}$, the radial aerodynamic force, was decomposed into its modal components. A vector plot of $f_{t x a}$, showing the contributions of $f_{c a}$, the chordwise aerodynamic force, and the modal components of $f_{r a}$, is shown for the five cases in fig. 21. Figure 21 shows that most of the change in the $2 / \mathrm{rev}$ in-plane aerodynamic force, $f_{t x a}$, due to changes in the mass distribution, arise from changes in the radial force, $f_{r a}$. The changes in $f_{r a}$, in turn, arise from changes in the first elastic bending modal component $(k=3)$. Changes from shifting the $\mathrm{cg}$ location arise primarily from changes in the chord wise force, $f_{c a}$. The out-of-plane aerodynamic force was not similarly decomposed, since fig. 14 shows that $\mathrm{f}_{\mathrm{tza}}$ is not a function of the bending modes.

Figure 22 presents a flowchart of the aerodynamic terms of fig. 14, and their components. Only the terms which were significantly affected by the changes in mass distribution and cg location are shown, and these have been decomposed into their basic modal elements. As fig. 21 showed, changes in blade mass distribution affected the radial aerodynamic force, $f_{\text {ra, }}$ primarily through the first elastic bending modal component $(k=3)$. Thus, altering the blade mass distribution affected the $2 /$ rev in-plane aerodynamic force in the same manner as it affected the $2 / \mathrm{rev}$ in-plane inertial force, namely through the first elastic bending modal elements.

The proportional change in the chordwise aerodynamic force, $\mathrm{f}_{\mathrm{ca}}$, caused by shifting the chordwise $\mathrm{cg}$ location can be traced, according to fig. 22 , to changes in the $2 / \mathrm{rev}$ component of the lift. Likewise, the changes in the single-blade normal force, $f_{\text {na }}$ can be traced to changes in the $3 / \mathrm{rev}$ component of the lift. The lift is a function of $\alpha$, which is affected primarily by changes in the first elastic torsion modal component of the elastic twist, $\theta_{\mathbf{e}}$. Figure 23 supports this claim. Shown are vector plots of the $2 / \mathrm{rev}$ and $3 / \mathrm{rev}$ components of the single-blade aerodynamic force normal to the hub plane, $f_{n a}$, and the force normal to the hub plane due only to the first elastic torsion mode, $f_{n}(p 1)$, where $f_{n(p 1)}$ is given by,

$$
f_{n(p 1)}=0.5 \rho(\Omega R)^{2} R U^{2} c q p 1 \int \cos ^{2} \phi \xi d r / R
$$


Figures $23 a$ and $b$ show that the difference vector $f_{n a}-f_{n(p 1)}$ remains unchanged from case to case, demonstrating that the changes seen in lift, and hence in $f_{n a}$, arise from changes in the first elastic torsion mode. Furthermore, figs. 23a and $b$ show that the single-blade aerodynamic force normal to the hub plane, $f_{n a}$, is primarily sensitive to the aft shift in blade cg location.

\subsection{Effect of Higher Harmonic Control on the Hub Shears}

The HHC algorithm described in section 3.3 was used to reduce the predicted hub shears for the highest-speed flight condition $\left(\mu=0.37, C_{T} / \sigma=0.066\right)$. The controller, or optimization algorithm, found a local minimum of the quadratic performance function, at which $J$ was reduced by $95 \%$ from the uncontrolled value. The square root of the performance function, $\sqrt{\mathrm{J}}$, is roughly the resultant $3 / \mathrm{rev}$ hub force. At this high speed, the HHC required a large amplitude of blade pitch control. The following control vector was used,

$$
\begin{aligned}
& \theta_{\text {con }}=\left[\left(\theta_{0}\right)_{3 c}\left(\theta_{0}\right)_{3 s}\left(\theta_{c}\right)_{3 c}\left(\theta_{c}\right)_{3 s}\left(\theta_{s}\right)_{3 c}\left(\theta_{s}\right)_{3 s}\right], \\
& \theta_{\text {con }}=[-1.59,-0.22,-1.27,0.26,-0.13,-2.12]
\end{aligned}
$$

The pilot controls were given by

$$
\theta_{\mathrm{p}}=13.13-2.45 \cos \Psi+7.56 \sin \Psi
$$

and the rotating frame HHC inputs corresponding to the control vector were

$$
\theta_{\text {II IC }}=-1.69 \cos 2 \Psi+0.19 \sin 2 \Psi-1.59 \cos 3 \Psi-0.22 \sin 3 \Psi+0.424 \Psi+0.19 \sin 4 \Psi
$$

Time history plots of the rotating frame pilot control inputs, and the superimposed HHC inputs, are shown in fig. 24. The maximum HHC control input was a positive $2.8 \mathrm{deg}$. occurring at $\psi=100 \mathrm{deg}$.

A bar chart showing the effect of HHC on the amplitudes of the force and moment coefficients is presented in fig. 25. Clearly, HHC managed to reduce the hub forces significantly. The hub moments, however, increased with the introduction of HHC. Thus, a performance function minimizing the amplitudes of all six loading components, rather than the amplitude and phase of just the hub forces, may be more desirable for reducing helicopter vibration. In addition, this analysis neglected shaft motion, which, if included, could change the hub shears produced by the rotor. The higher harmonic control also increased the power required by $10 \%$. This increase was primarily due to an increase in profile power. Higher harmonic control increased the net angles of attack primarily on the retreating side of the rotor disk, thus increasing the profile power. This suggests also including the power in the quadratic performance function.

Vector plots of the aerodynamic and inertial contributions to the fixed-frame hub shears, shown in fig. 26, illustrate the mechanism of hub shear reduction. Figure 26 shows the hub forces without HHC, with HHC, and the difference between the two, which is the perturbation of the forces due to HHC. In addition, fig. 26 shows the individual inertial (I) and aerodynamic (A) components of each total (T) vector. The total perturbation vector is created by generating large aerodynamic and rigid flap inertial perturbations. Thus, the hub force reduction is manifested not simply by direct cancellation of a particular hub-force component through generation of an opposing aerodynamic force, but by phase cancellation of large inertial and acrodynamic force components of the same order of magnitude. The effectiveness of HHC, therefore, depends not only on variations in blade angles of attack to achieve appropriate changes in the aerodynamic forces, but also on blade inertial characteristics to achieve appropriate changes in the inertial forces.

\section{Conclusions/Discussion}

Three topics related to the hub loads of the SA349/2 aircraft were investigated in this paper. First, correlations were presented between measured and predicted hub forces and moments, to examine the effect of the wake model and to develop confidence in the analysis. The last two subjects were theoretical investigations using CAMRAD and CAMRAD/JA. The effect on the hub loads of altering the blade mass distribution and cg location was examined. Finally, the effect of using higher harmonic control to reduce hub shear forces was studied.

Using the CAMRAD analysis to predict measured hub loads resulted in the following conclusions: 
1. The $1 / \mathrm{rev}$ rotating frame and mean nonrotating frame forces and moments were well predicted by the CAMRAD analysis using either a uniform inflow or a nonuniform inflow wake model, reflecting the good prediction of rotor trimmed forces and moments.

2. Predictions of the $2 / \mathrm{rev}$ and $4 / \mathrm{rev}$ rotating frame and corresponding $3 / \mathrm{rev}$ fixed-frame forces and moments are significantly improved with the use of a nonuniform inflow model in the analysis. However, despite the significant improvement in the predictions of the oscillatory loads when using a nonuniform inflow model, the predictions are in error by approximately $30 \%$, particularly at high advance ratio.

Changing the blade mass distribution by shifting weight alternately outboard and inboard, and shifting the cg location aft and forward of $24.7 \%$ chord, affected hub loads at high speed as follows:

1. The in-plane nonrotating frame $3 / \mathrm{rev}$ hub forces and moments both increased when shifting the mass from outboard to inboard (with a corresponding $24 \%$ increase in the blade mass), and when shifting the $\mathrm{cg}$ location from forward to aft.

2. The overall out-of-plane nonrotating frame $3 / \mathrm{rev}$ forces and moments decreased when shifting mass both outboard and inboard, and when shifting the $\mathrm{cg}$ from forward to aft.

3. Changing the blade mass distribution affected only the inertial part of hub forces, through changes in the first elastic bending modal components: the blade bending mode shape, the blade modal frequency, and the modal inertia.

4. Shifting the blade cg location affected both the inertial and aerodynamic components of the hub forces. Changes in the aerodynamic component were traced to changes in the first elastic torsion modal component. Changes in the inertial component were traced to the the aerodynamic forcing function, which was also influenced by the first elastic torsion mode.

Introducing an HHC control algorithm into the CAMRAD/JA analysis had the following effects on the predicted hub shear forces for high speed flight:

1. Using HHC, CAMRAD/JA predicted a reduction in the total resultant $3 / \mathrm{rev}$ hub force of $95 \%$, primarily by introducing large but opposing aerodynamic and inertial components of the hub forces. The evidence that HHC affects inertial as well as aerodynamic hub forces suggests that blade design optimization and HHC techniques should be considered together for the most beneficial results.

2. The rotor power increased by $10 \%$ when $\mathrm{HHC}$ was introduced. The change was due to an increase in profile power caused by increased angles of attack on the retreating side of the rotor disk.

These results are particular to the SA349/2 aircraft. In addition, this study of the effects of blade structural changes and higher harmonic control on hub loads is purely theoretical (no measurements were made). However, the approach of this investigation, which shows how the calculated results of a large computer code can be examined in detail, is very general. This type of study serves to elucidate the physical mechanisms for changes in rotor loads caused by blade (or other) design changes, which can be useful both for modifying rotor designs and improving rotor analyses.

\section{$\underline{7 .}$ References}

1. R.H. Blackwell: "Blade Design for Reduced Helicopter Vibration" presented at the American Helicopter Society National Specialists' Meeting on Helicopter Vibration, Hartford, Connecticut, November 1981.

2. R.B. Taylor: "Helicopter Vibration Reduction by Rotor Blade Modal Shaping" presented at the 38th American Helicopter Society Forum, Anaheim, California, May 1982.

3. A. Landgrebe and M. Davis: "Analysis of Potential Helicopter Vibration Reduction Concepts" presented at the American Helicopter Society and NASA Ames Research Center 2nd Decennial Specialists' Meeting in Rotorcraft Dynamics, Moffett Field, California, November 1984.

4. S.B.R. Kottapalli: "Hub Loads Reduction by Modification of Blade Torsional Response" presented at the 39th American Helicopter Society Forum, St. Louis, Missouri, May 1983.

5. F. Tarzanin and R. Vlaminck: "Investigation on the Effect of Blade Sweep on Rotor Vibratory Loads" NASA CR 166526, October 1983.

6. C.F. Niebanck: "An Examination of the Relations Between Rotor Vibratory Loads and Airframe Vibrations" presented at the American Helicopter Society and NASA Ames Research Center 2nd Decennial Specialists' Meeting on Rotorcraft Dynamics, Moffett 
Field, California, November 1984.

7. R. Blackwell, R. Murrill, W. Yeager, and P. Mirick: "Wind Tunnel Evaluation of Aeroelastically Conformable Rotors" presented at the 36th American Helicopter Society Forum, Washington D.C., May 1980.

8. D.K. Young, F.J. Tarzanin, and D.L. Kunz: "Use of Blade Sweep to Reduce 4/rev Hub Loads" presented at the 43rd American Helicopter Society Forum, St. Louis, Missouri, May 1987.

9. R. Heffernan and M. Gaubert. "Structural and Aerodynamic Loads and Performance Measurements of an SA349/2 Helicopter with an Advanced Geometry Rotor" NASA TM 88370, November 1986.

10. G. Yamauchi, R. Heffernan and M. Gaubert: "Correlation of SA349/2 Helicopter Flight Test Data with a Comprehensive Rotorcraft Model" NASA TM 88351, February 1987

11. M. Gaubert and G. Yamauchi: "Prediction of SA349/2 GV Blade Loads in High Speed Flight Using Several Rotor Analyses" presented at the 43rd American Helicopter Society Forum, St. Louis, Missouri, May 1987.

12. R. Heffernan: "Effect of Helicopter Blade Dynamics on Blade Aerodynamic and Structural Loads" presented at the AIAA Dynamics Specialists' Conference, Paper No. AIAA-87-0919-CP, Monterey, California, April 1987.

13. B. Pcleau and D. Petot: "Aeroclastic Response of Rotor Loads in Forward Flight" presented at the XIII European Rotorcraft Forum, Arles, France, September 1987.

14. G. Yamauchi, R. Heffernan, and M. Gaubert: "Hub and Blade Structural Loads Measurements of an SA349/2 Helicopter" NASA TM 101040, 1988.

15. W. Johnson: "Development of a Comprehensive Analysis for Rotorcraft - I, Rotor Model and Wake Analysis" Vertica, Vol. 5, No. 2, 1981.

16. W. Johnson: "Development of a Comprehensive Analysis for Rotorcraft - II, Aircraft Model, Solution Procedure and Applications" Vertica, Vol. 5, No. 3, 1981.

17. W. Johnson: "A Comprehensive Analytical Model of Rotorcraft Aerodynamics and Dynamics" NASA TM 81182, June 1980.

18. W. Johnson: "Self-Tuning Regulators for Multicyclic Control of Helicopter Vibration" NASA TP 1996, March 1982.

19. M. Achache and M. Polychroniadis: "Development of an Experimental System for Active Control of Vibrations on Helicopters -- Development Methodology of an Airborne System" Vertica, Vol. 11, No 1/2, 1987. 
Table 1. SA349/2 AIRCRAFT CHARACTERISTICS

$\begin{array}{lc}\text { Aircraft gross weight } & 19,600 \mathrm{~N} \\ \text { Main } \begin{array}{l}\text { rotor } \\ \text { number of blades }\end{array} & 3 \\ \begin{array}{l}\text { radius } \\ \text { blade chord }\end{array} & 5.25 \mathrm{~m} \\ \text { solidity } & 0.35 \mathrm{~m} \\ \text { blade tip speed } & 0.064 \\ & 212 \mathrm{rpm} \\ \text { Tail rotor blade tip speed } & 215 \mathrm{rpm} \\ & \\ \text { Engine type } & \text { Astazou XIV H rated at } 550 \mathrm{kw}\end{array}$

Table 2. Flight Parametcrs for Selected Conditions.

\begin{tabular}{lcccc}
\hline Flight Condition & V3101 & V3103 & V3105 & V3106 \\
Altitude (m) & 306.2 & 276.7 & 317.2 & 342.2 \\
TAS (m/s) & 30.2 & 56.4 & 74.4 & 79.0 \\
Load Factor & 1.0 & 1.0 & 1.0 & 1.0 \\
$\mu$ & 0.14 & 0.26 & 0.35 & 0.37 \\
C $/ \sigma \quad 0.0662$ & 0.0662 & 0.0628 & 0.0655 \\
Helicopter weight (kg) & 1999.0 & 1991.0 & 1979.0 & 1973.0 \\
Static Pressure (mbar) & 978.0 & 981.3 & 976.7 & 973.8 \\
Static Temperature ( $\left.{ }^{\circ} \mathrm{C}\right)$ & 9.2 & 10.0 & 11.2 & 11.4 \\
Estimated hub drag (N) & 36.0 & 305.0 & 511.0 & 597.0
\end{tabular}

Table 3. Condition V3106. Bending, $v_{k}$, and torsion, $\omega_{k}$, mode frequencies

\begin{tabular}{|c|c|c|c|c|c|c|}
\hline Mode & $\mathrm{k}$ & Baseline & $\begin{array}{l}\text { Mass } \\
\text { outboard }\end{array}$ & $\begin{array}{l}\text { Mass } \\
\text { inboard }\end{array}$ & $\mathrm{CG}$ aft & CG forward \\
\hline Rigid lag & 1 & 0.58 & 0.55 & 0.63 & 0.58 & 0.58 \\
\hline Rigid flap & 2 & 1.03 & 1.02 & 1.03 & 1.03 & 1.03 \\
\hline $\begin{array}{l}\text { 1st elastic } \\
\text { bending }\end{array}$ & 3 & 2.81 & 3.30 & 2.43 & 2.81 & 2.81 \\
\hline $\begin{array}{l}\text { 2nd elastic } \\
\text { bending }\end{array}$ & 4 & 4.76 & 5.31 & 4.27 & 4.77 & 4.77 \\
\hline $\begin{array}{l}\text { 3rd elastic } \\
\text { bending }\end{array}$ & 5 & 5.24 & 5.83 & 4.85 & 5.23 & 5.24 \\
\hline $\begin{array}{l}\text { 1st elastic } \\
\text { torsion }\end{array}$ & 1 & 4.13 & 4.13 & 4.13 & 4.13 & 4.13 \\
\hline $\begin{array}{l}\text { 2nd elastic } \\
\text { torsion }\end{array}$ & 2 & 12.81 & 12.81 & 12.81 & 12.81 & 12.81 \\
\hline
\end{tabular}


Table 4. Condition V3106. Generalized modal inertias, $I_{q k}$

\begin{tabular}{lcccccc}
\hline Mode & $\mathrm{k}$ & $\begin{array}{c}\text { B a seline } \\
\text { Qutboard }\end{array}$ & $\begin{array}{l}\text { Mass } \\
\text { inboard }\end{array}$ & Mass & CG aft & CG forward \\
\hline Rigid lag & 1 & 0.86 & 1.04 & 0.68 & 0.86 & 0.86 \\
Rigid flap & 2 & 0.98 & 1.15 & 0.81 & 0.98 & 0.98 \\
$\begin{array}{l}1 \text { st elastic } \\
\text { bending }\end{array}$ & 3 & 0.66 & 0.61 & 0.52 & 0.66 & 0.66
\end{tabular}

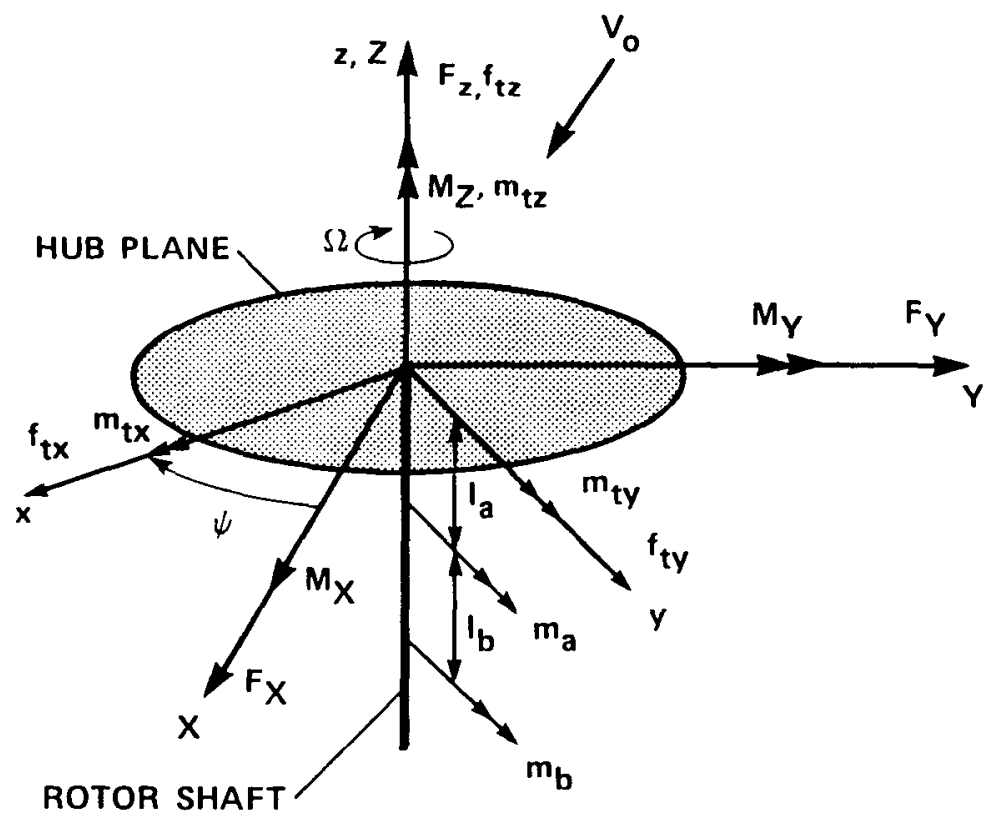

Figure 1. Hub force and moment diagram. 


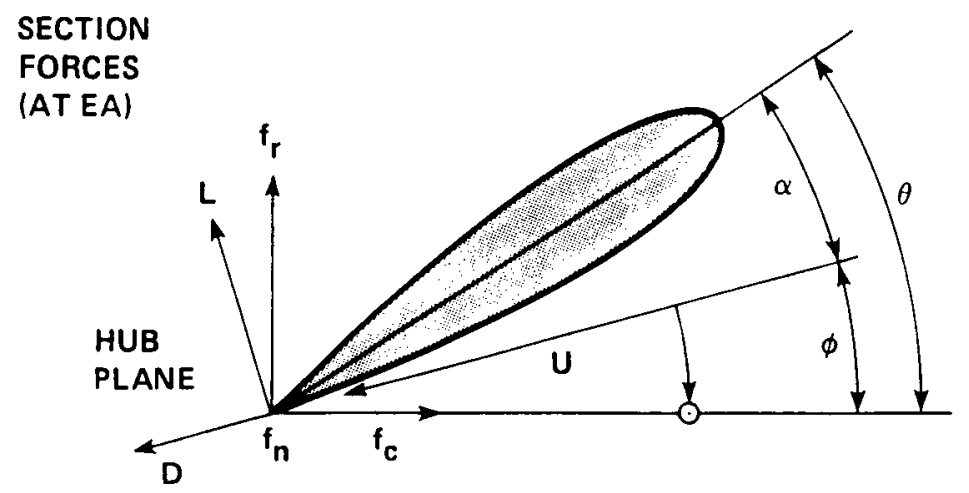

(a)

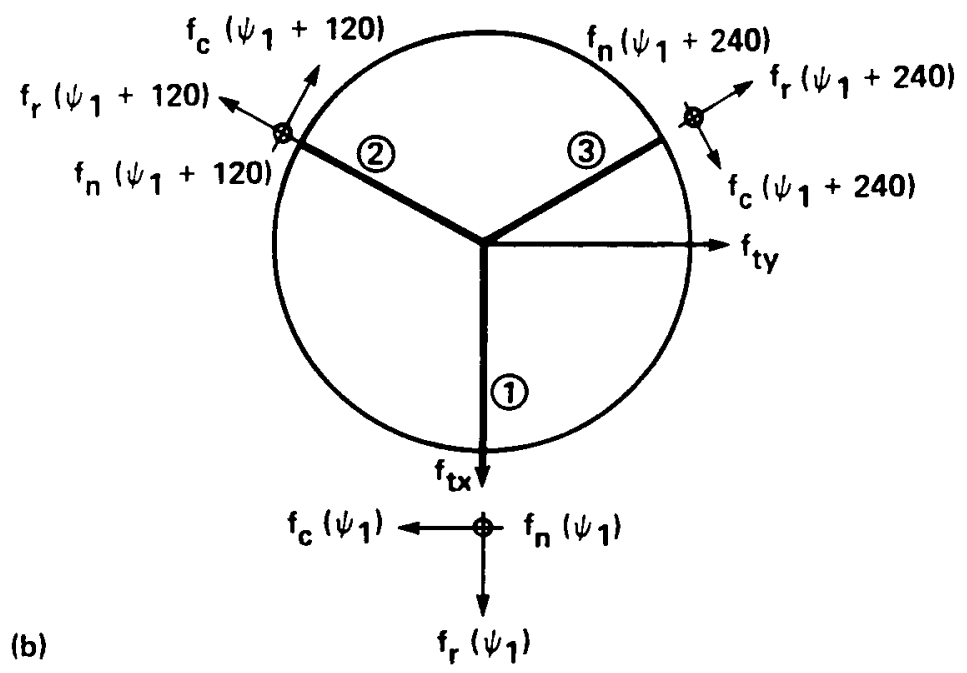

(c)

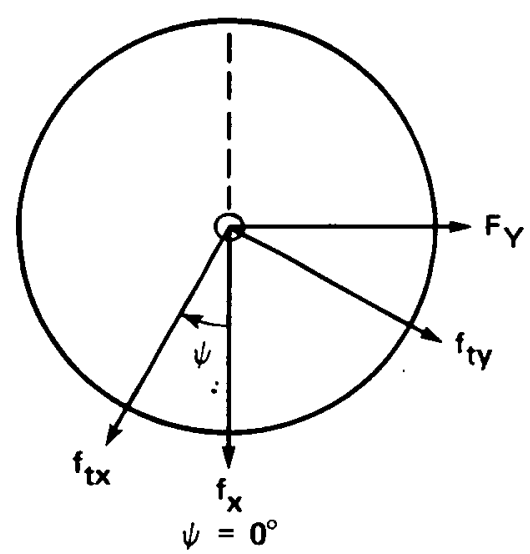

Figure 2. Diagram of a) single-blade hub forces, b) total rotating-frame hub forces, and c) total nonrotating-frame hub forces. 

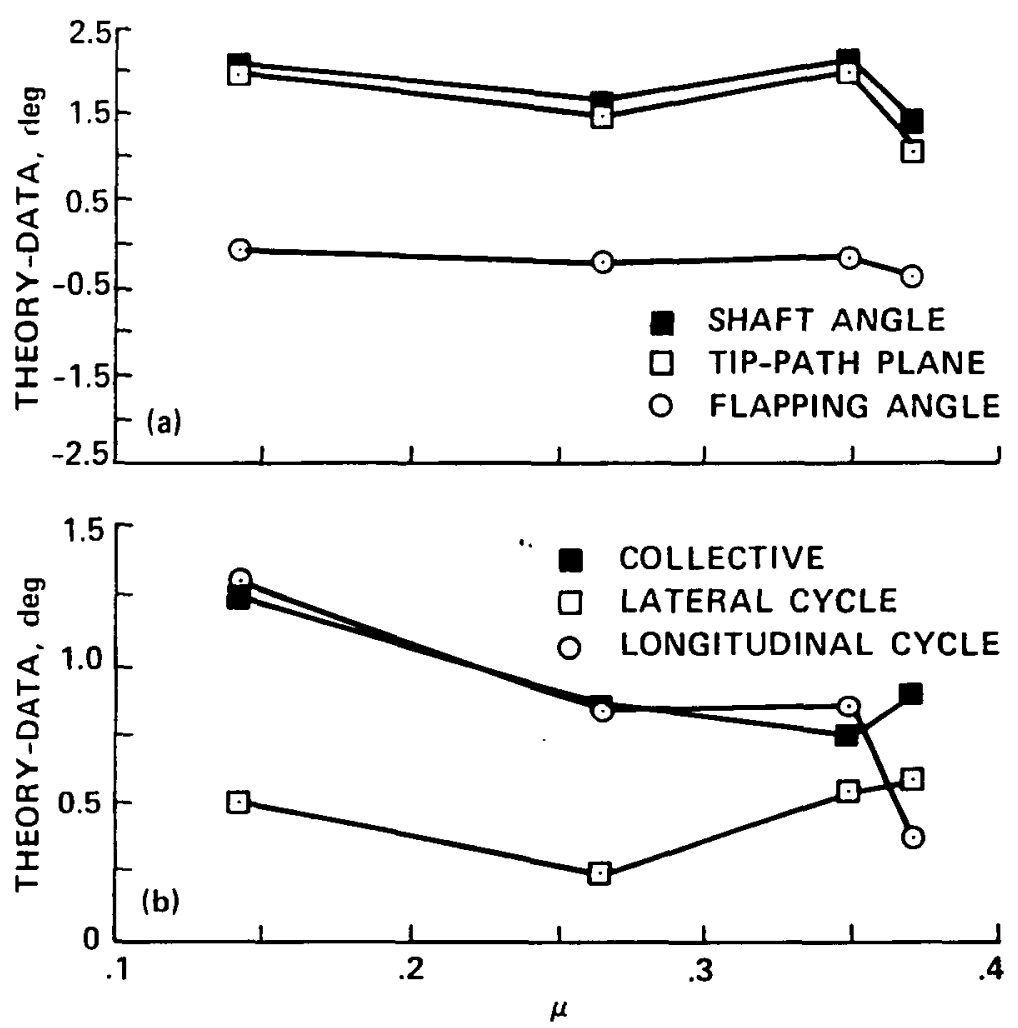

Figure 3. Rotor trim predictions,

a. difference between predicted and measured rotor disk orientation, b. difference between predicted and measured rotor control angles. 

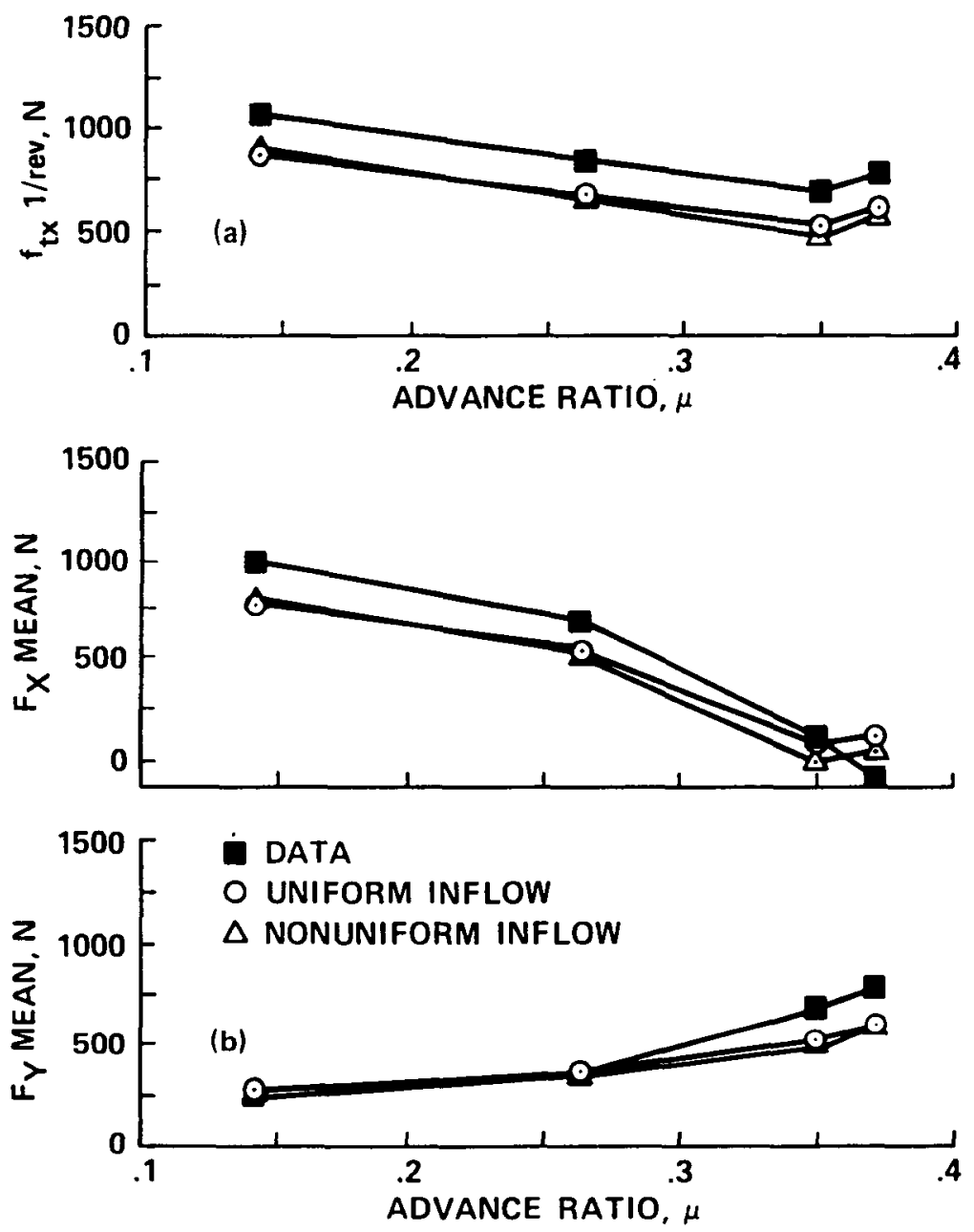

Figure 4. In-plane hub force correlations,

a. total $1 /$ rev rotating-frame force, $f_{t x}$,

b. total mean nonrotating-frame forces, $F_{X}$ and $F_{Y}$. 

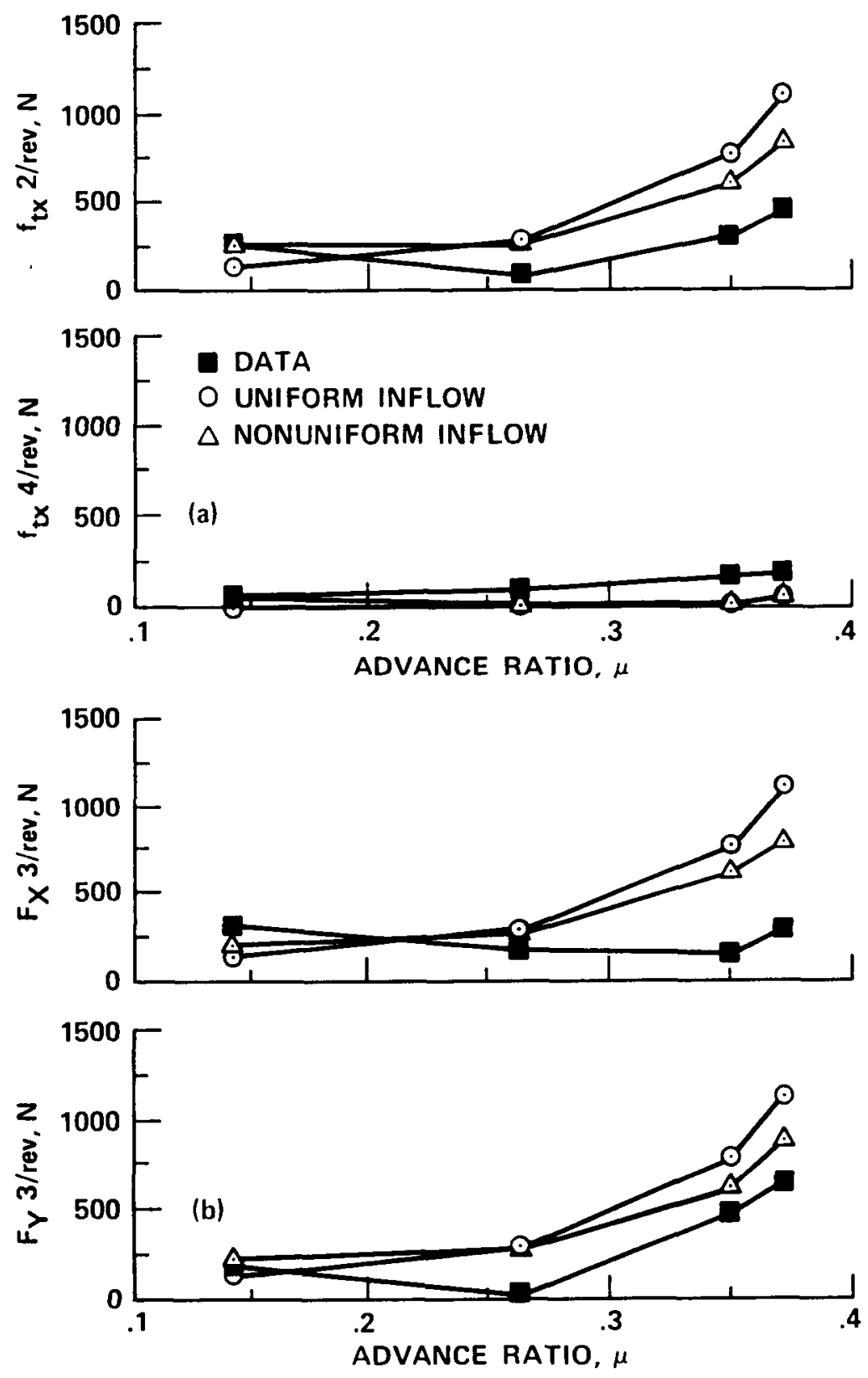

Figure 5. In-plane hub force correlations,
a. total $2 / \mathrm{rev}$ and $4 / \mathrm{rev}$ rotating-frame force, $\mathrm{f}_{\mathrm{tx}}$,
b. total $3 /$ rev nonrotating-frame forces, $F_{X}$ and $F_{Y}$. 


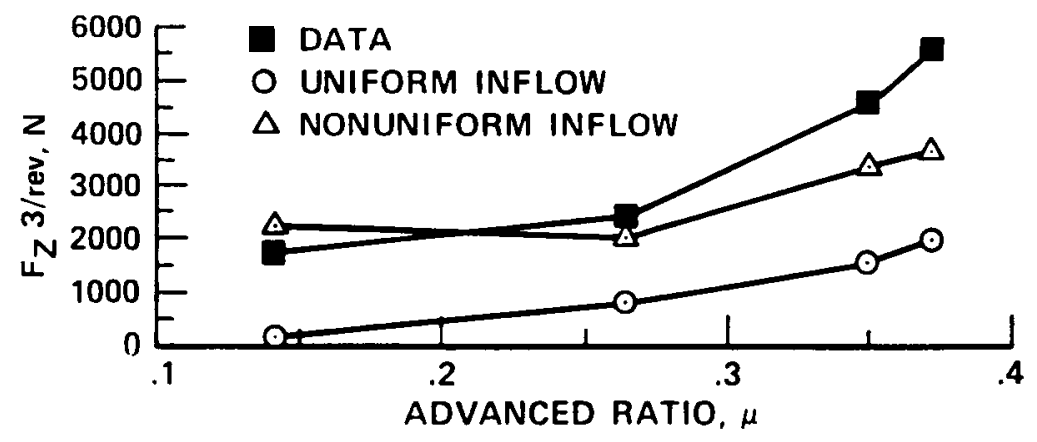

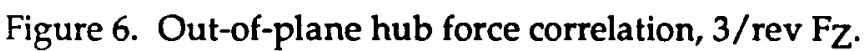
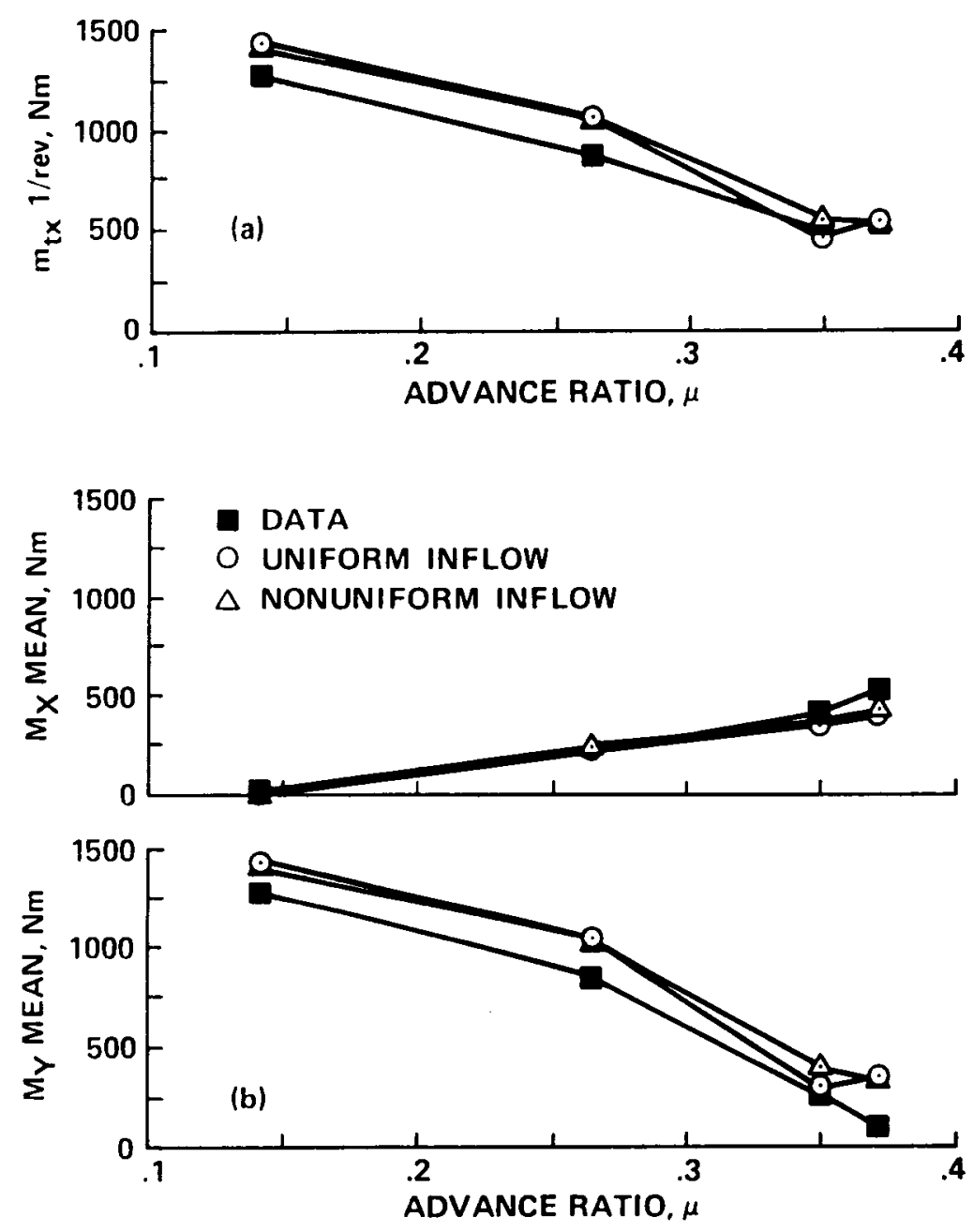

Figure 7. In-plane hub moment correlations,

a. total $1 /$ rev rotating-frame moment, $m_{t x}$,

b. total mean nonrotating-frame moments, $\mathrm{MX}_{X}$ and $\mathrm{MY}_{\mathrm{Y}}$. 

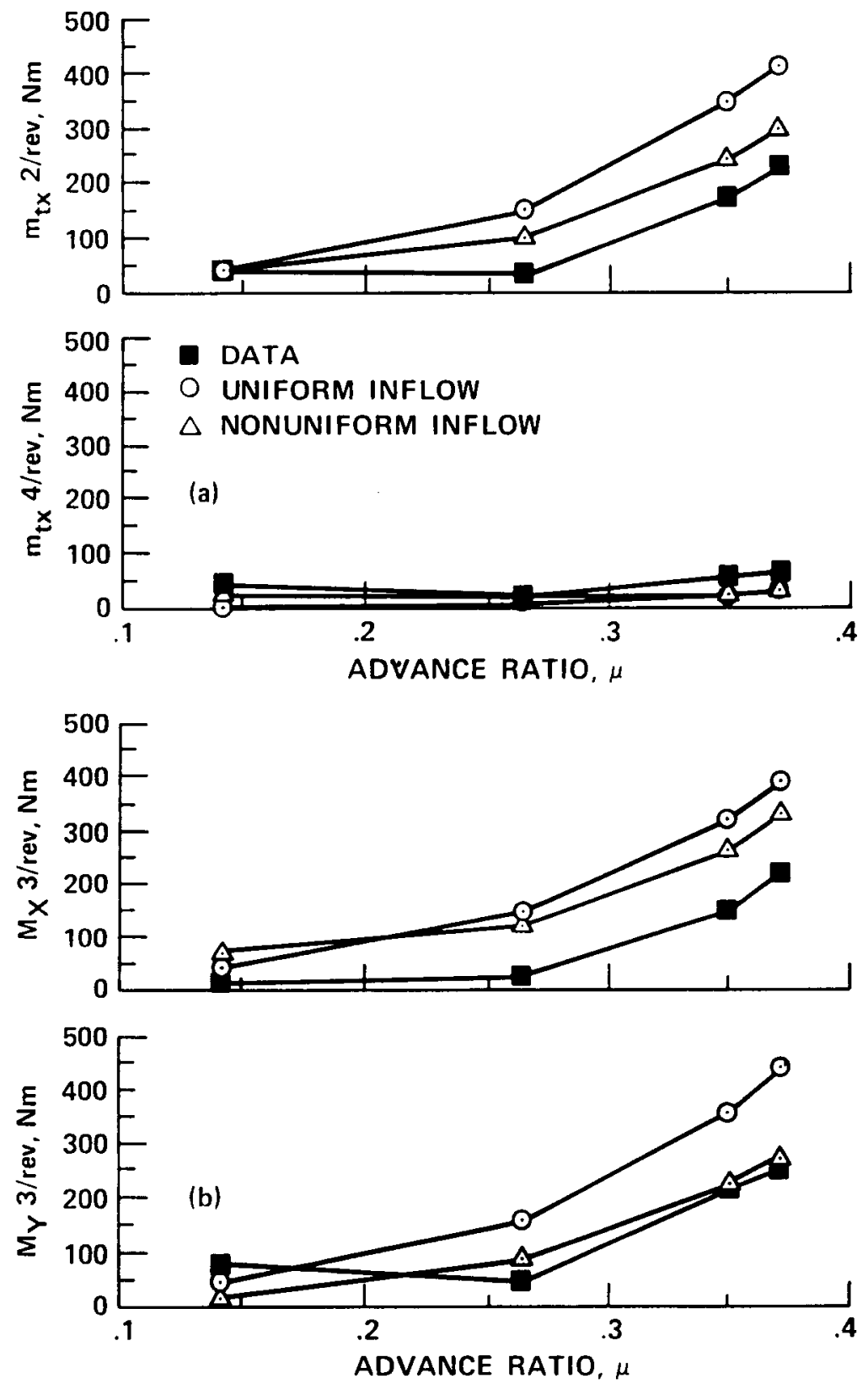

Figure 8. In-plane hub moment correlations,

a. total $2 / \mathrm{rev}$ and $4 / \mathrm{rev}$ rotating-frame moment, $m_{\mathrm{tx}}$,

b. total $3 /$ rev nonrotating-frame moment, $\mathrm{MX}$ and $\mathrm{MY}$. 

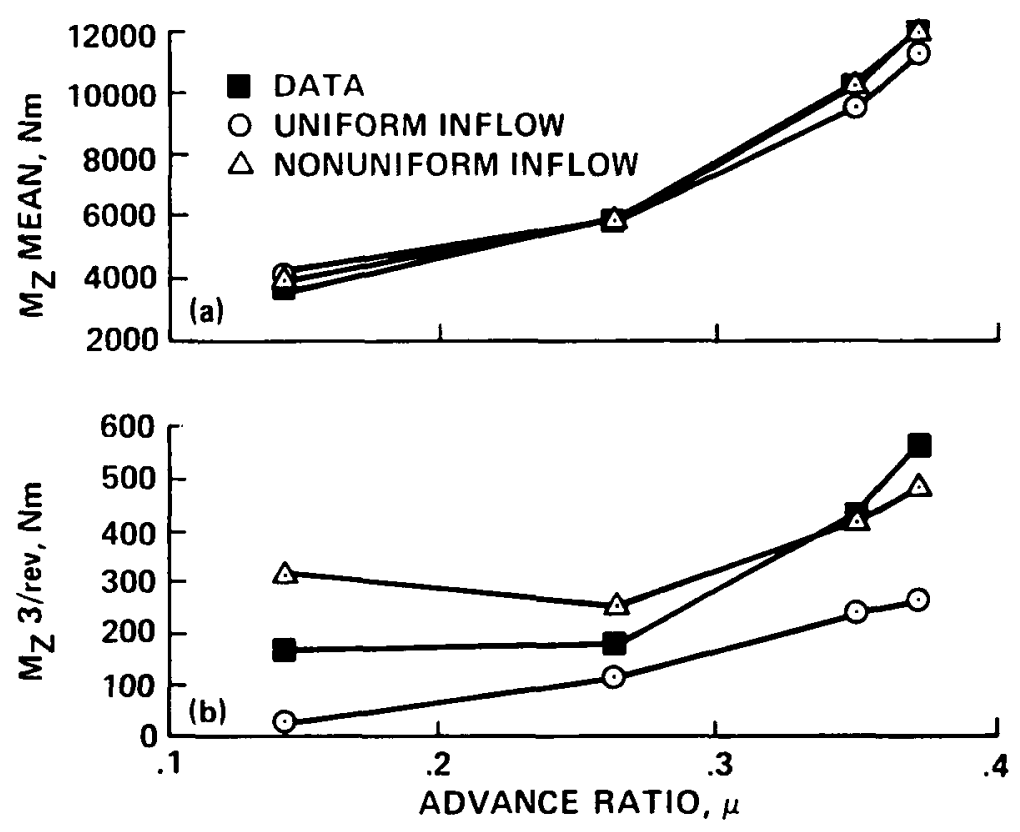

Figure 9. Out-of-plane hub force correlation,

a. total mean moment, $\mathrm{MZ}$,

b. total 3/rev moment, $\mathrm{MZ}$.

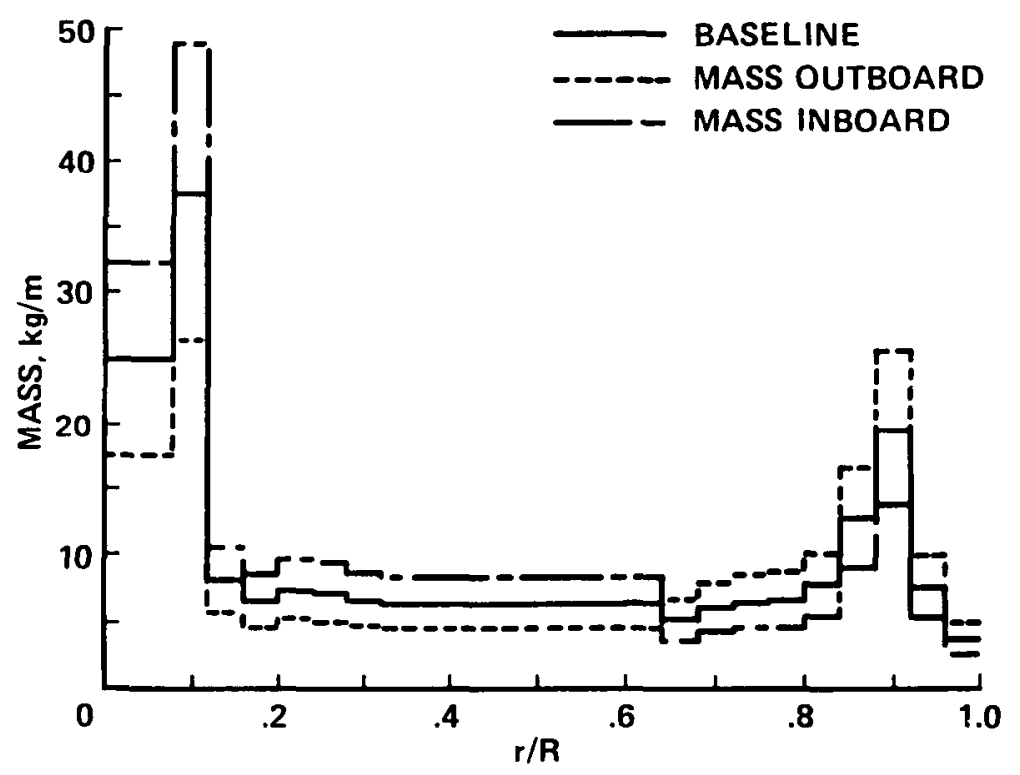

Figure 10. Blade mass distributions. 

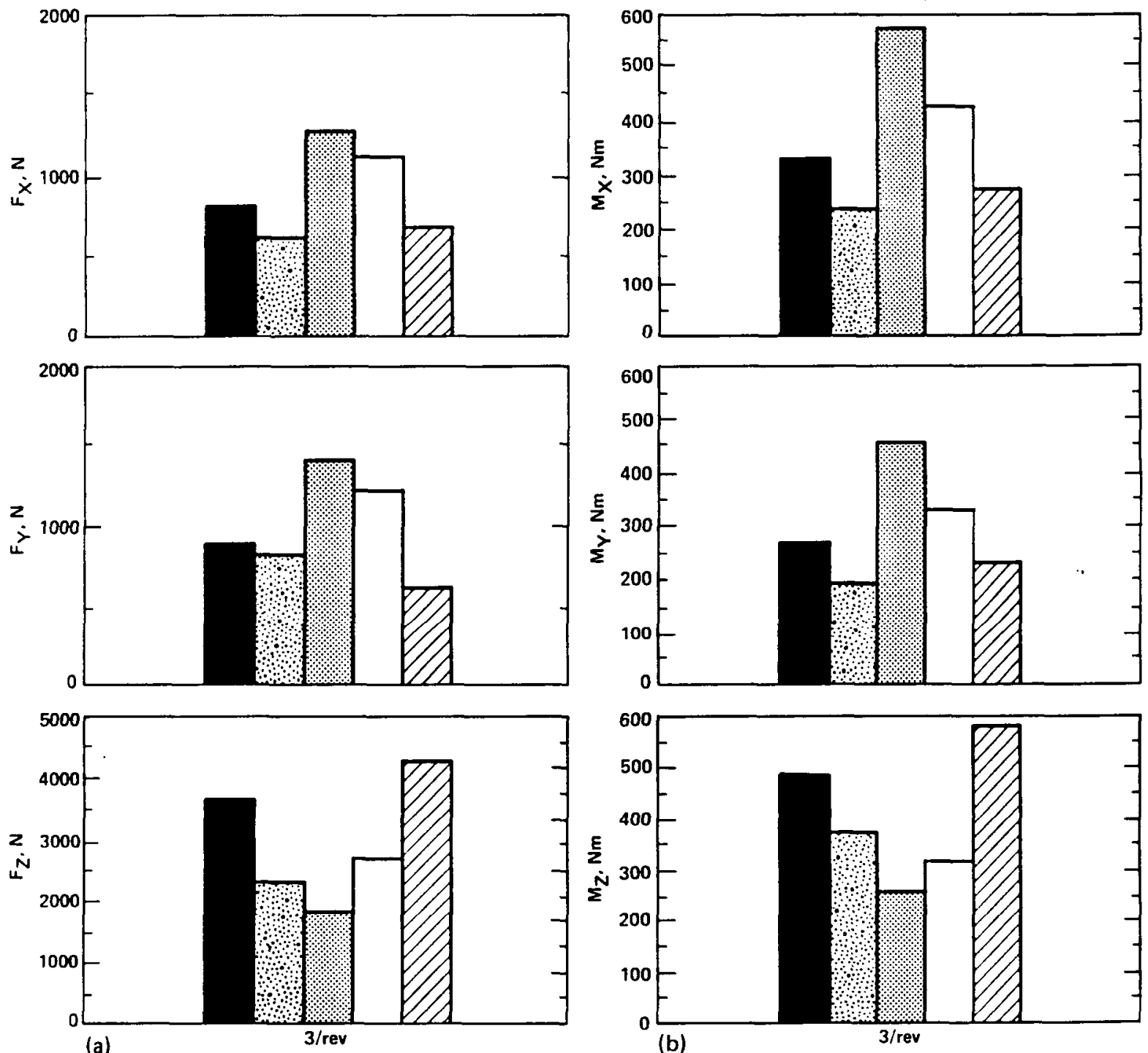

(a)

BASELINE

MASS OUTBOARD

$\square$ CG AFT

MASS INBOARD

Figure 11. Influence of changing the blade mass distribution and chordwise cg location on nonrotating-frame hub loads $\left(\mu=0.37, \mathrm{C}_{\mathrm{T}} / \sigma=0.066\right)$,

a) Hub forces: $F_{X}, F_{Y}, F_{Z}$,

b) Hub moments: $M_{X}, M_{Y}, M_{Z}$. 
(a)

MASS INBOARD

MASS OUTBOARD

$\longrightarrow$ BASELINE

-1000
-

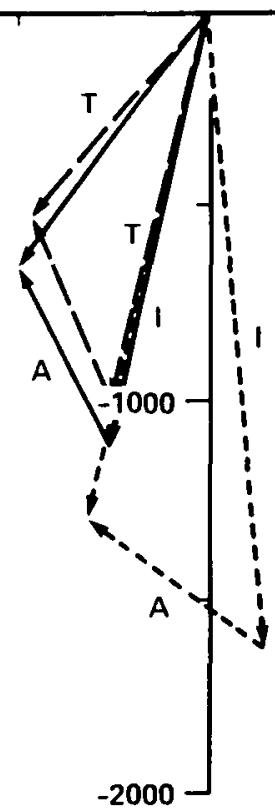

(b)

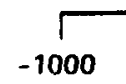

\section{CG FORWARD}

$\longrightarrow$ CG AFT

$\longrightarrow$ BASELINE

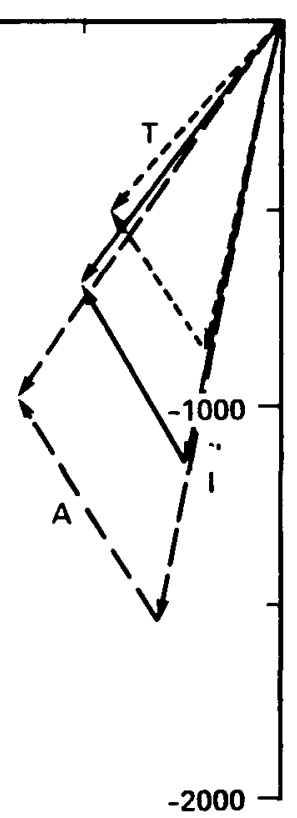

Figure 12. Vector representation of the total (T) rotating-frame force, $2 / \mathrm{rev} f_{t x}$, and the inertial (I) and aerodynamic (A) components,

a. Effect of changing blade mass distribution,

b. Effect of shifting chordwise cg location.

(a)

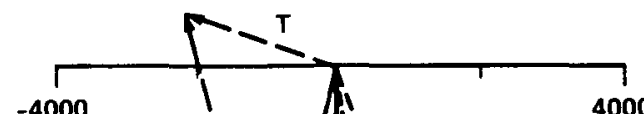

MASS INBOARD MASS OUTBOARD BASELINE

$-4000$

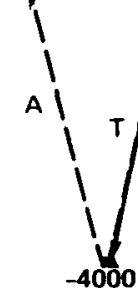

贷

is

is

ais

紧

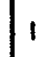

A 1

'

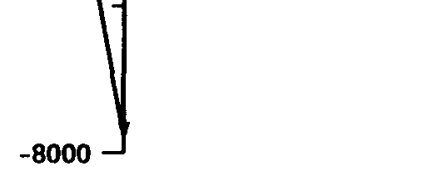

(b)

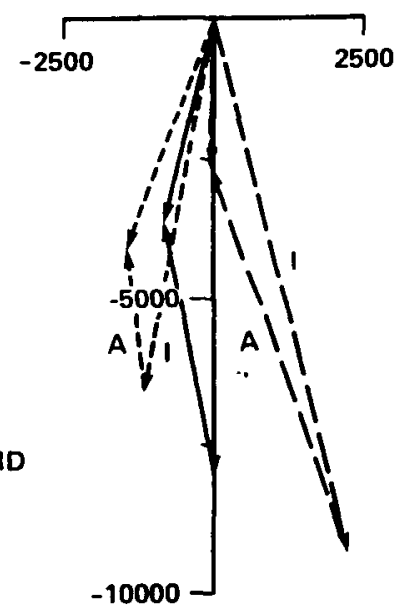

Figure 13. Vector representation of the total $(T)$ rotating-frame force, $3 / \mathrm{rev} f_{t z}$, and the inertial (I) and aerodynamic (A) components,

a. Effect of changing blade mass distribution,

b. Effect of shifting chordwise cg location. 


\section{ORIGNAL PAGE IS \\ OF POOR QUALTY}

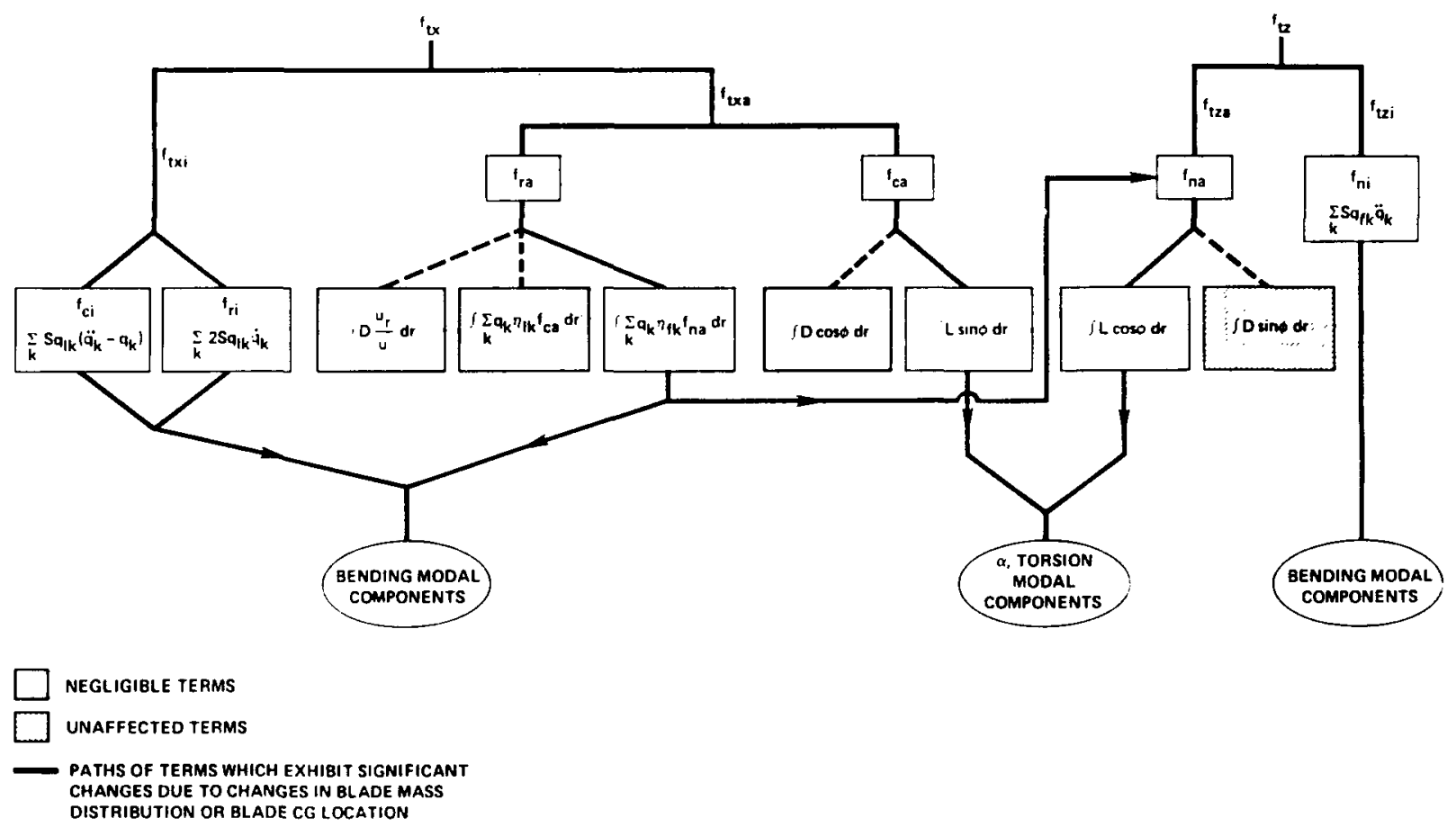

Figure 14. Schematic of the aerodynamic and inertial terms. 

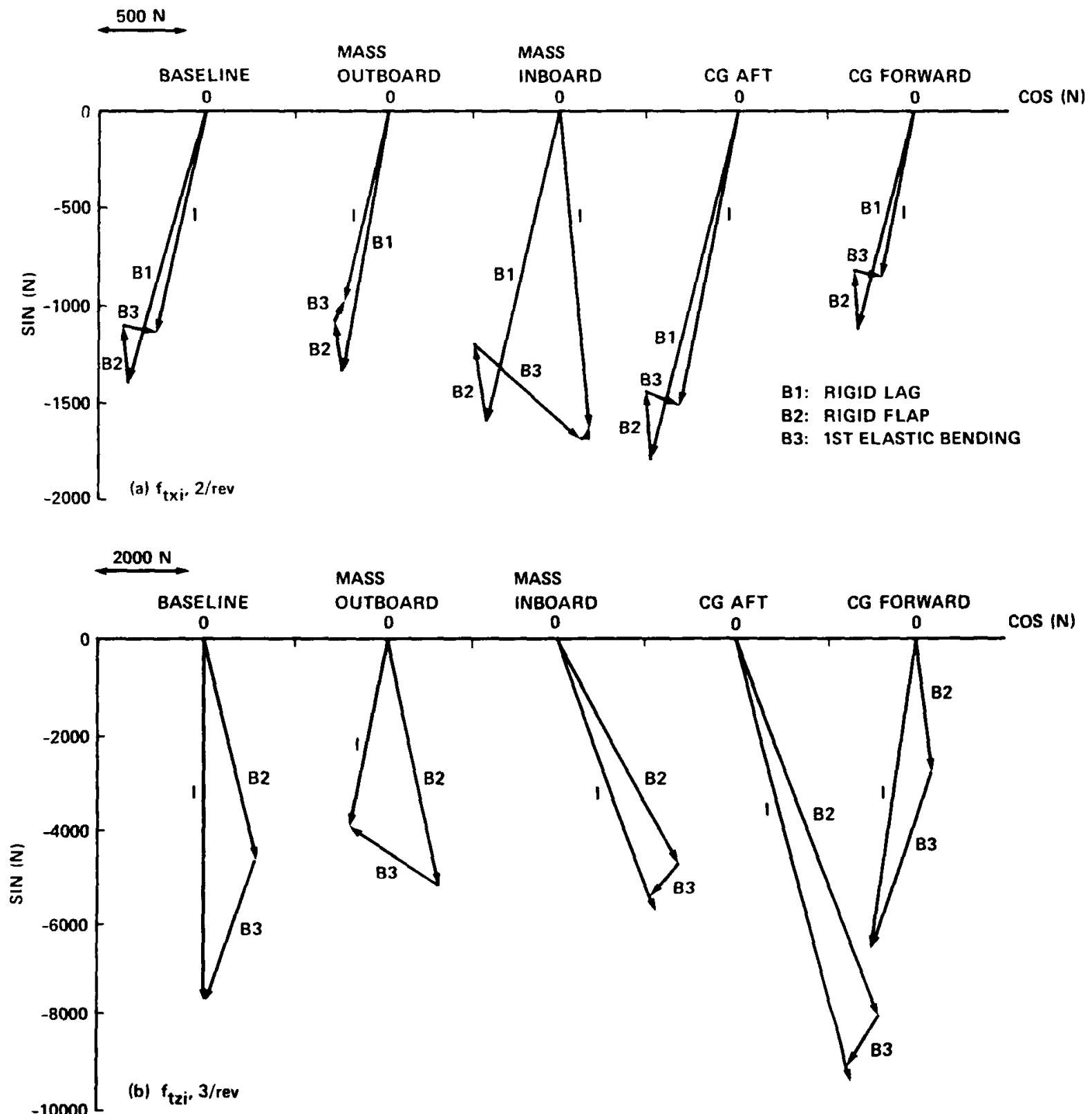

Figure 15. Bending mode contributions to the total rotating-frame inertial hub forces (I), a. $2 / \mathrm{rev} \mathrm{ftxi}$, b. $3 / \mathrm{rev} \mathrm{ftzi}$. 

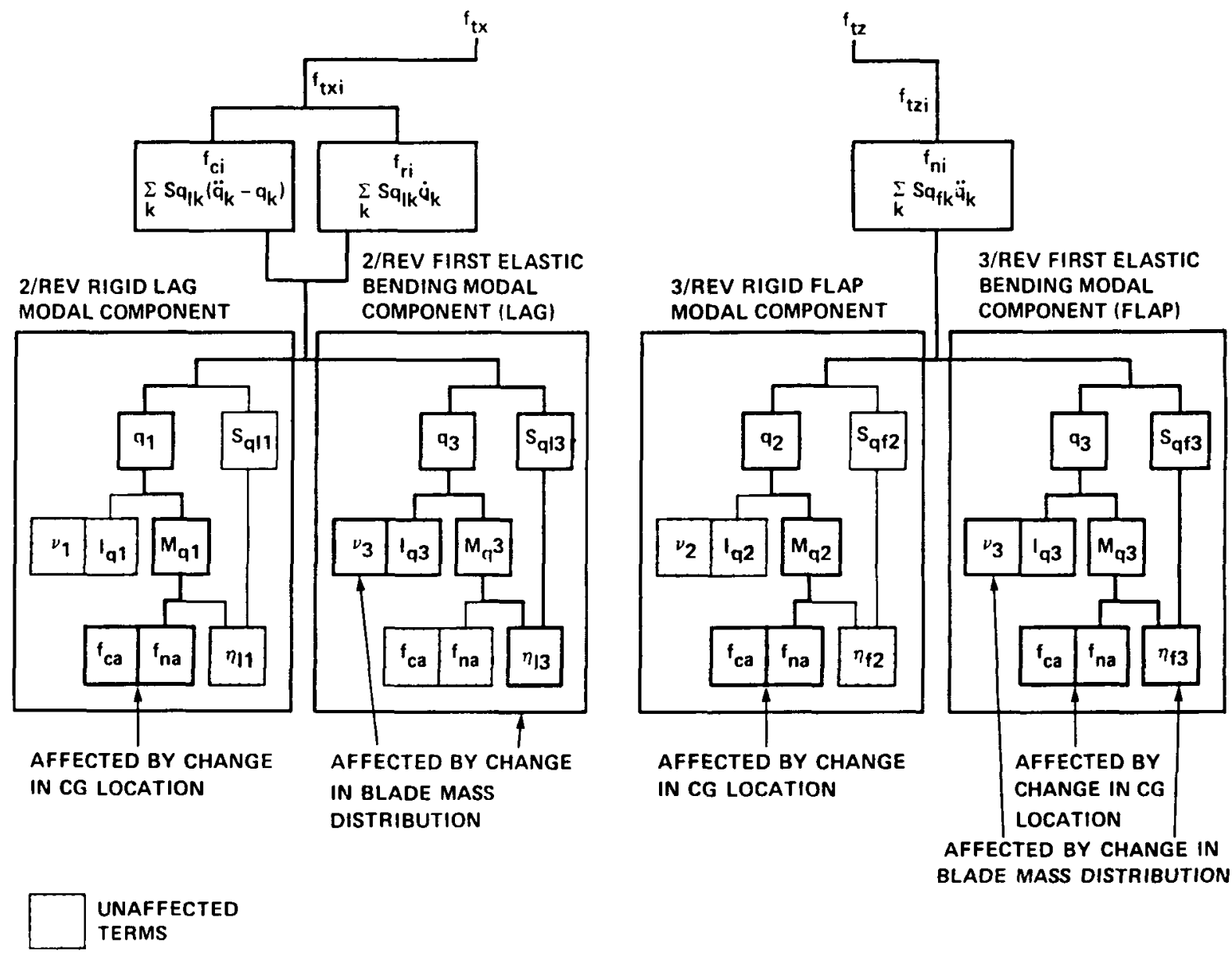

Figure 16. Schematic breakdown of the inertial forces, showing terms influenced by changing the blade mass distribution and chordwise cg location. 

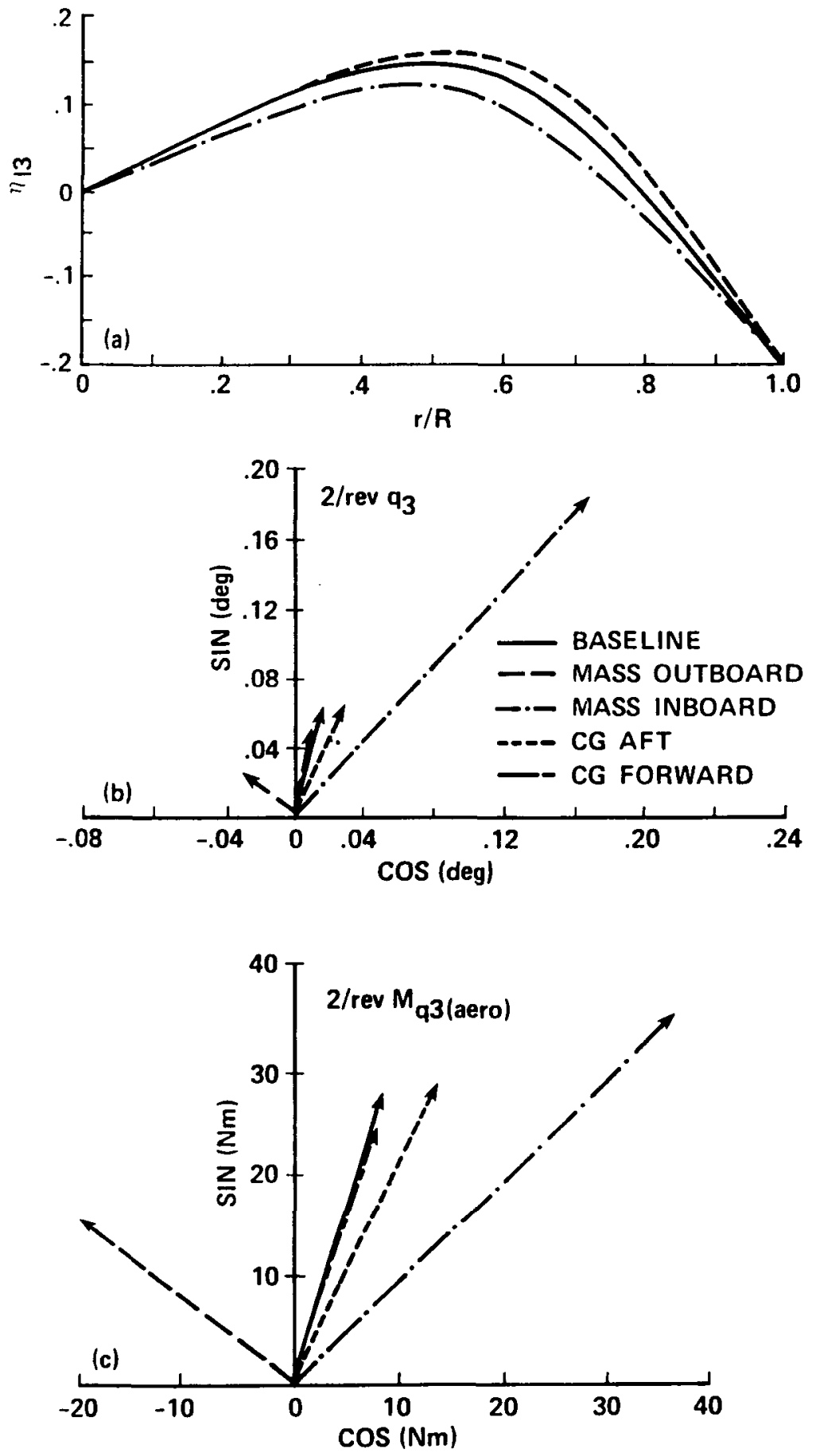

Figure 17. Effect of changing blade properties on the $2 /$ rev first elastic bending modal component:

a. lag component of the first elastic bending mode shape, $\eta_{13}$,

b. first elastic bending degree of freedom, $q_{3}$,

c. first elastic bending component of the aerodynamic moment, $\mathrm{M}_{\mathrm{q} 3(\mathrm{aero}) \text {. }}$ 

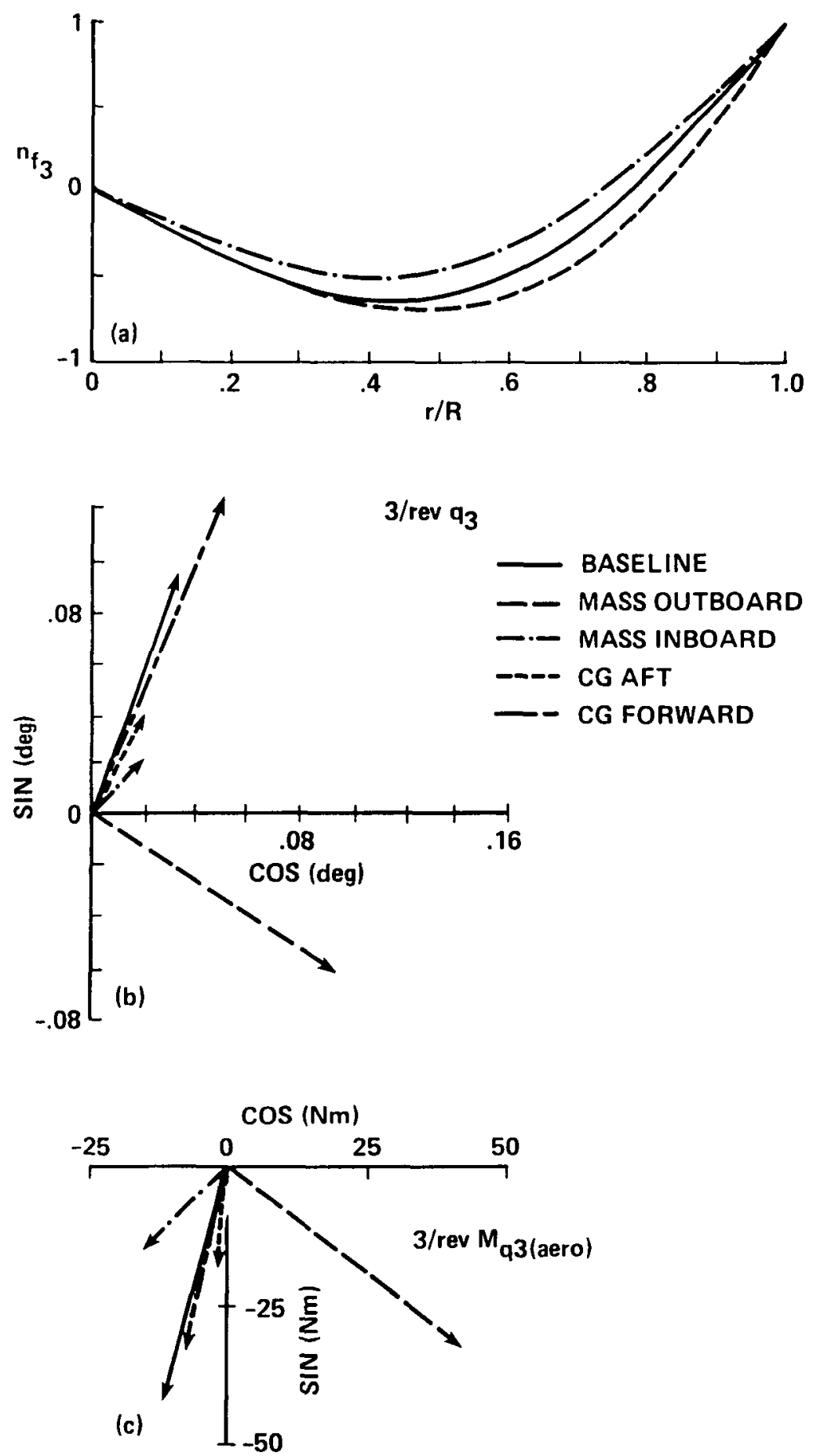

Figure 18. Effect of changing blade properties on the $3 / \mathrm{rev}$ first elastic bending modal component:

a. flap component of the first elastic bending mode shape, $\eta_{\mathrm{f} 3}$

b. first elastic bending degree of freedom, q3

c. First elastic bending component of the aerodynamic forcing function, $\mathrm{M}_{\mathrm{q} 3 \text { (aero). }}$ 


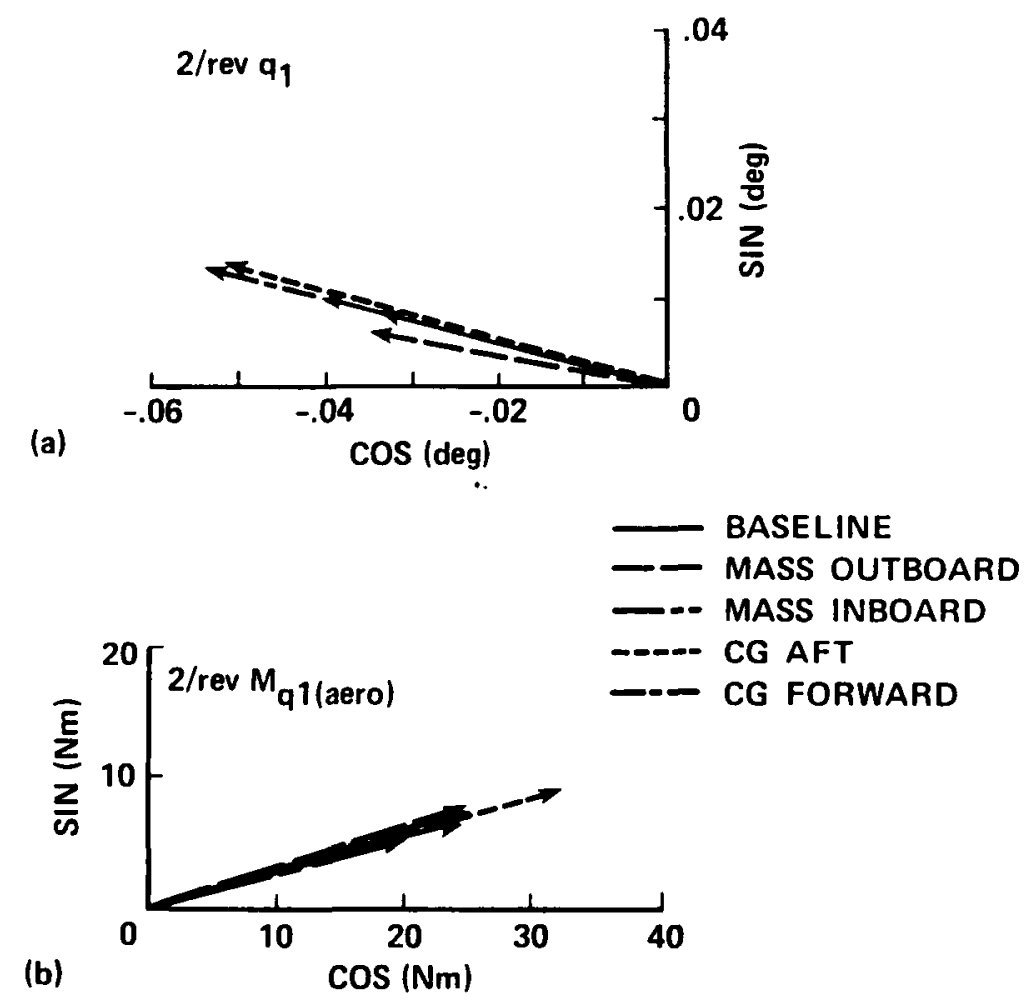

Figure 19. Effect of changing blade properties on the $2 /$ rev rigid lag modal component:

a. rigid lag degree of freedom, $q_{1}$,

b. rigid lag component of the aerodynamic moment, $\mathrm{M}_{\mathrm{q} 1 \text { (aero). }}$ 


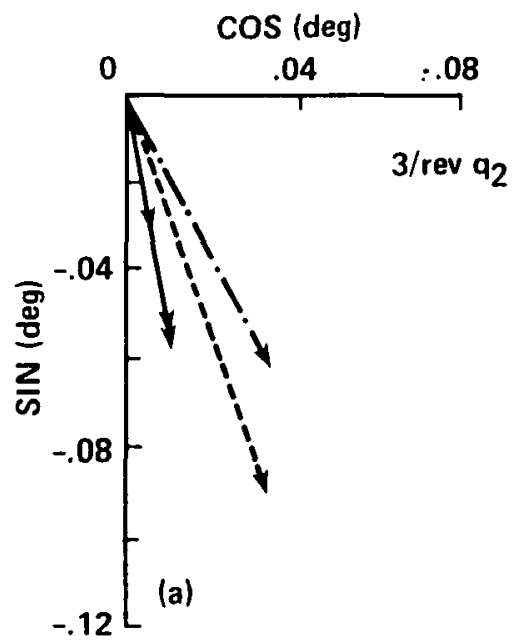

$$
\begin{array}{ll}
- & \text { BASELINE } \\
-- & \text { MASS OUTBOARD } \\
-- & \text { MASS INBOARD } \\
-- & \text { CG AFT } \\
-- & \text { CG FORWARD }
\end{array}
$$

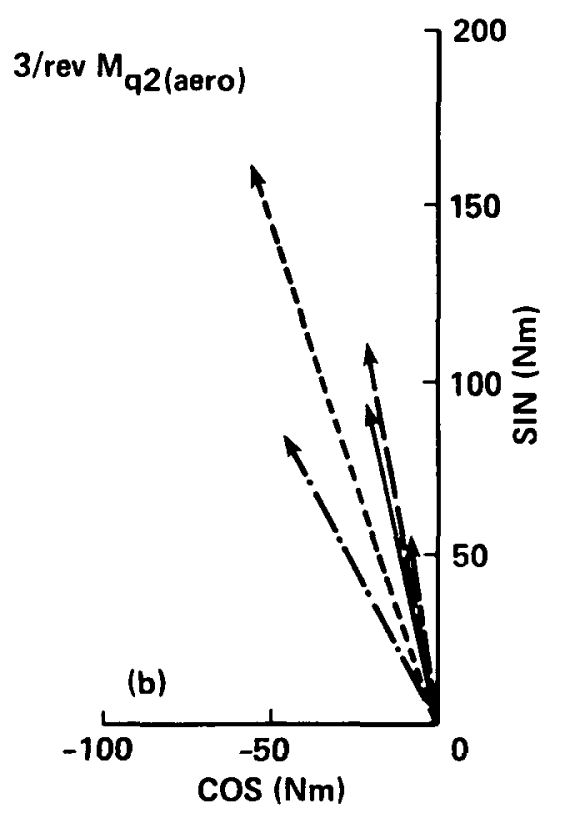

Figure 20. Effect of changing blade properties on the $3 /$ rev rigid flap modal component:

a. rigid flap degree of freedom, $q_{2}$

b. rigid flap component of the aerodynamic moment, $\mathrm{M}_{\mathrm{q} 2(\mathrm{aero}) \text {. }}$ 
$f_{r a}$ : AERODYNAMIC COMPONENT OF $f_{r}$

B2: RIGID FLAP

83: FIRST ELASTIC BENDING

$f_{c a}$ : AERODYNAMIC COMPONENT OF $i_{c}$

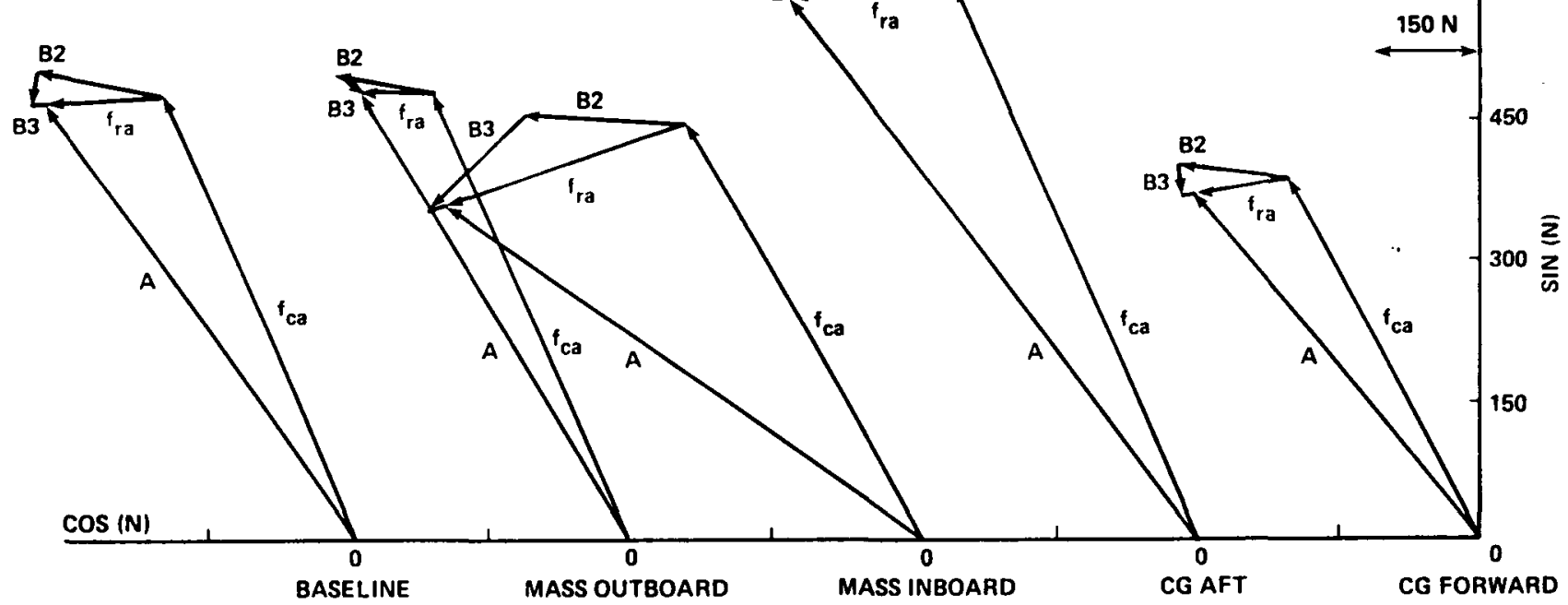

Figure 21. Single-blade aerodynamic force contributions to the total in-plane rotating-frame aerodynamic hub force (A), including the modal components of $\mathrm{f}_{\mathrm{ra}}$.

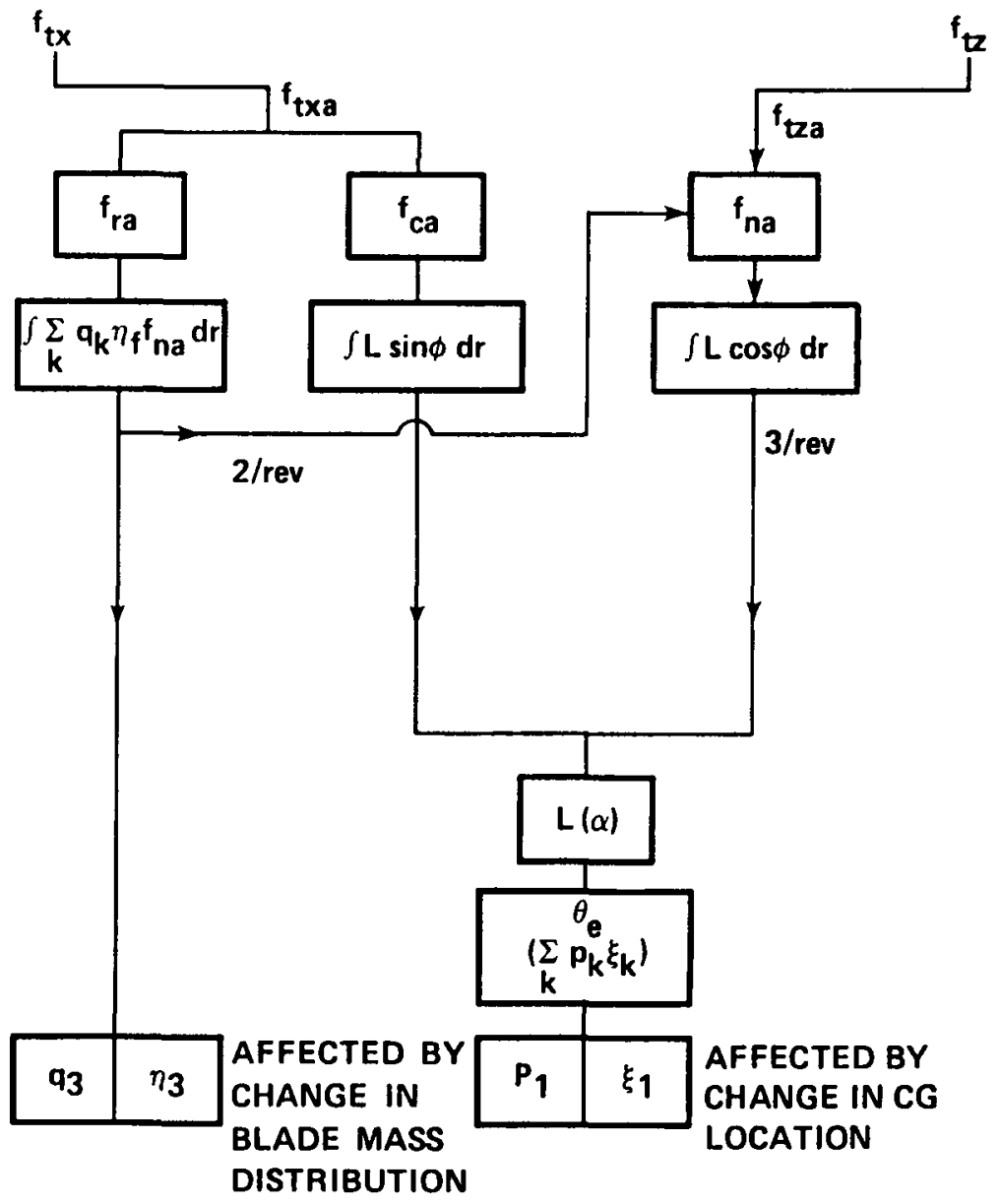

Figure 22. Schematic breakdown of the aerodynamic forces, showing terms influenced by changing the blade mass distribution and chordwise cg location. 


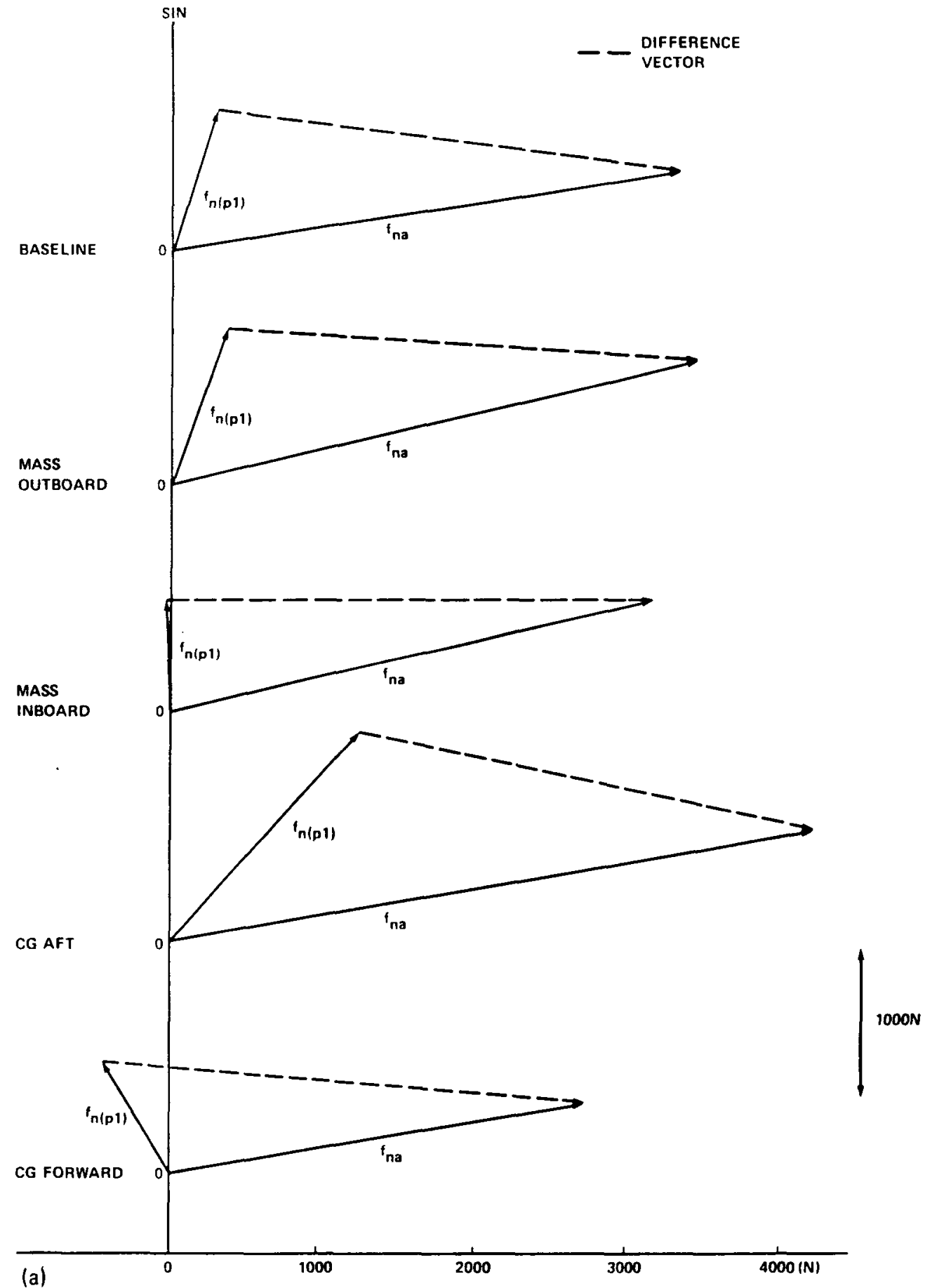

Figure 23. Vector plot of the single-blade rotating-frame aerodynamic force, $f_{z a}$, the first elastic torsion component of $f_{\mathrm{za}}, \mathrm{f}_{\mathrm{z}}(\mathrm{p} 1)$, and the difference vector between the two,

a. $2 / \mathrm{rev}$,

b. $3 /$ rev. 


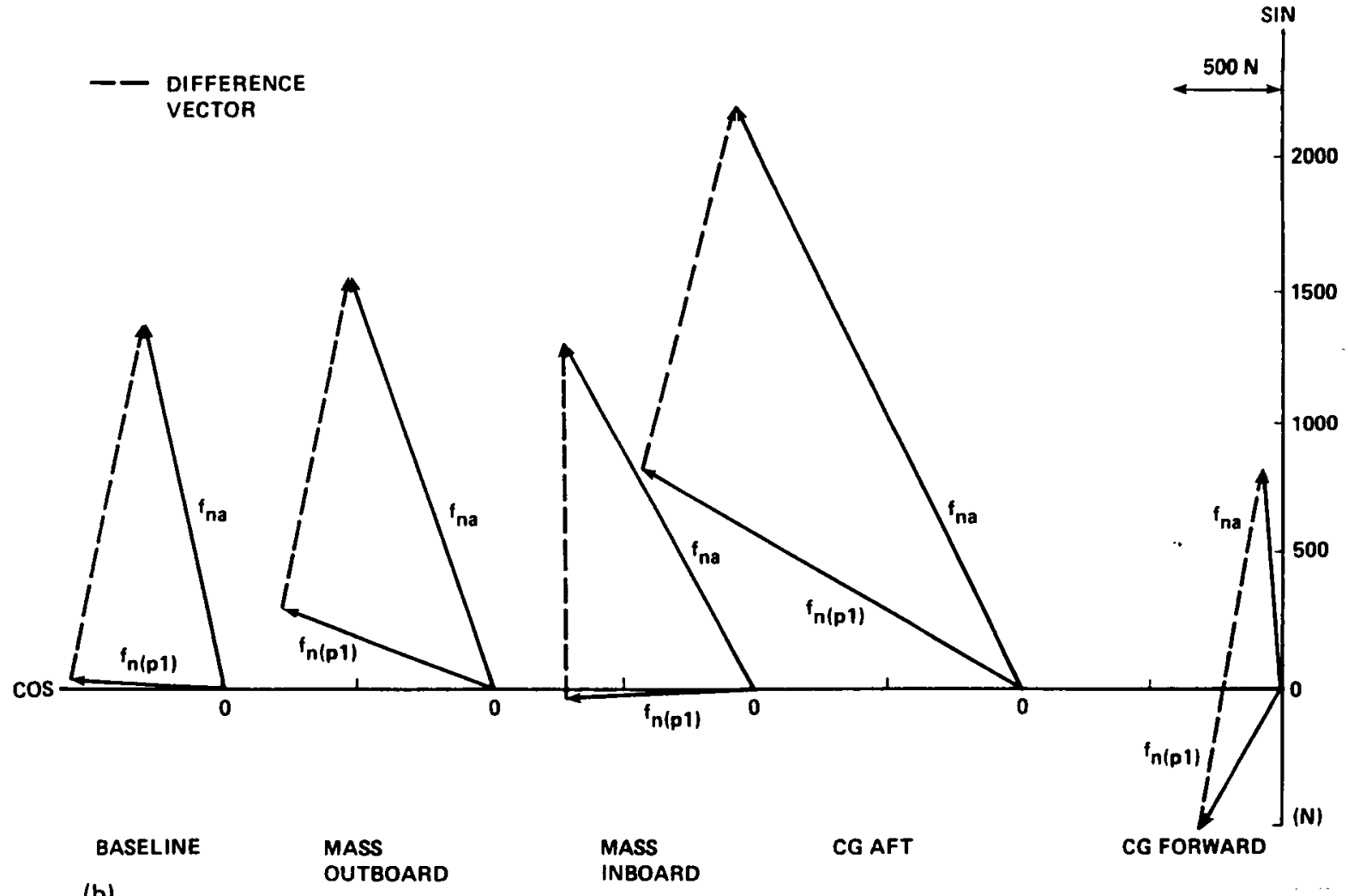

(b)

Figure 23. Concluded.

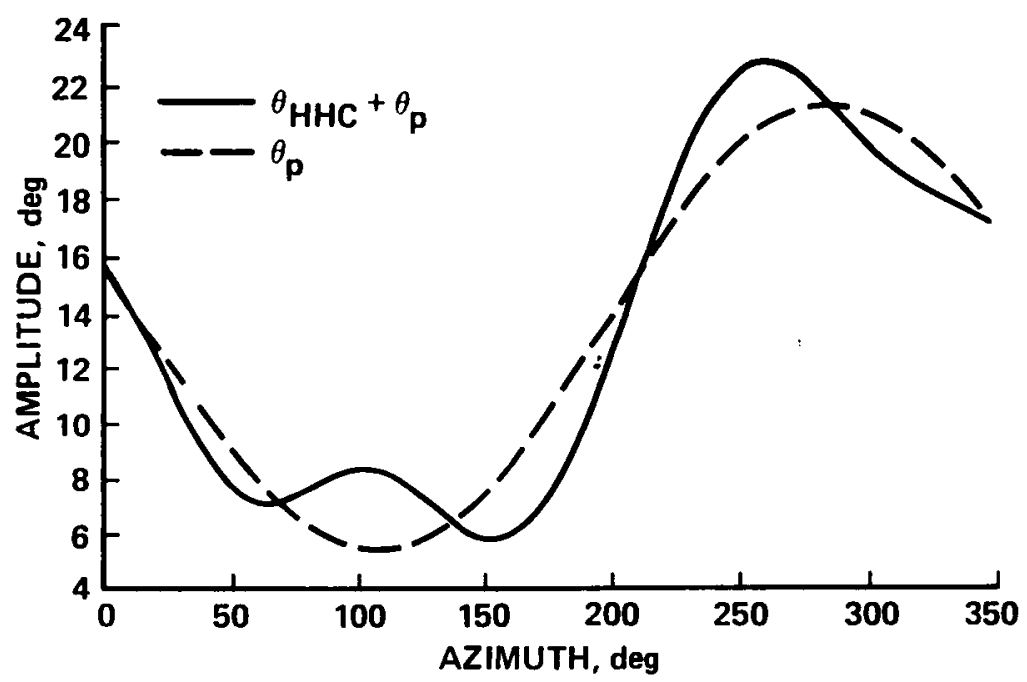

Figure 24. Time history of the commanded control input, and the superimposed higher harmonic control command. 

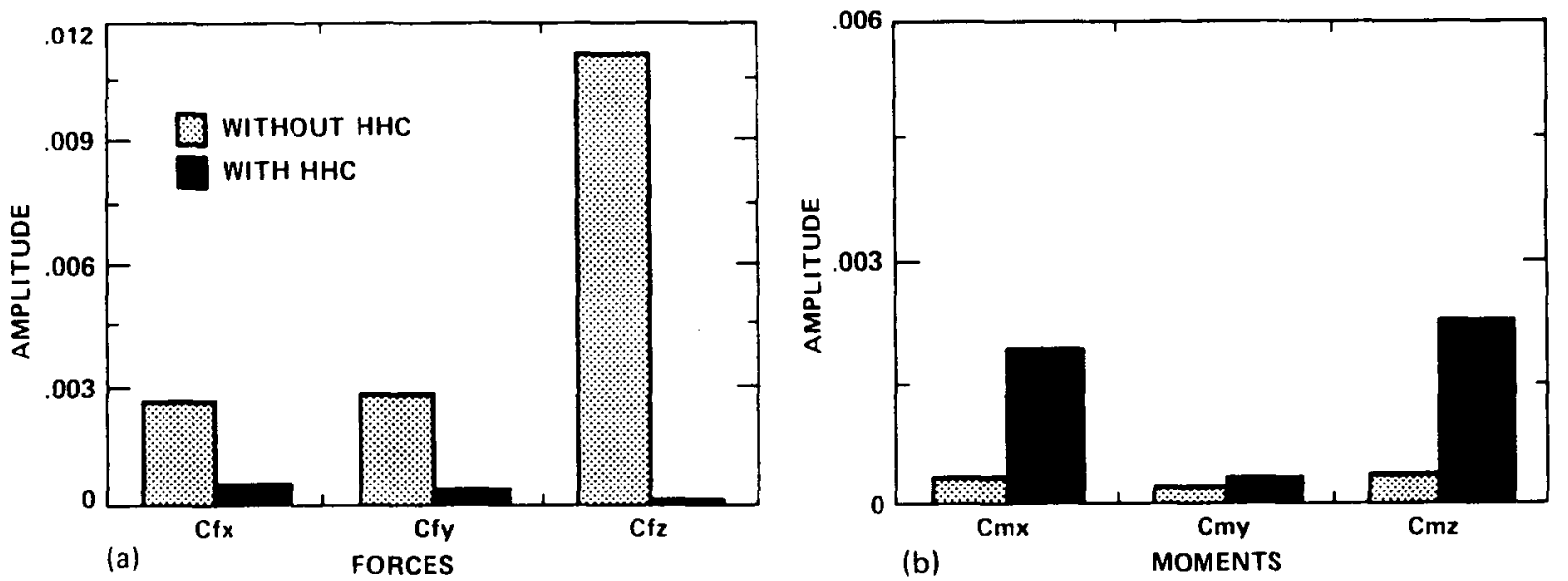

Figure 25. Influence of higher harmonic control on the amplitudes of the $3 /$ rev nonrotatingframe hub loads,

a. hub forces,

b. hub moments.

(a) $F_{X}, 3 /$ REV

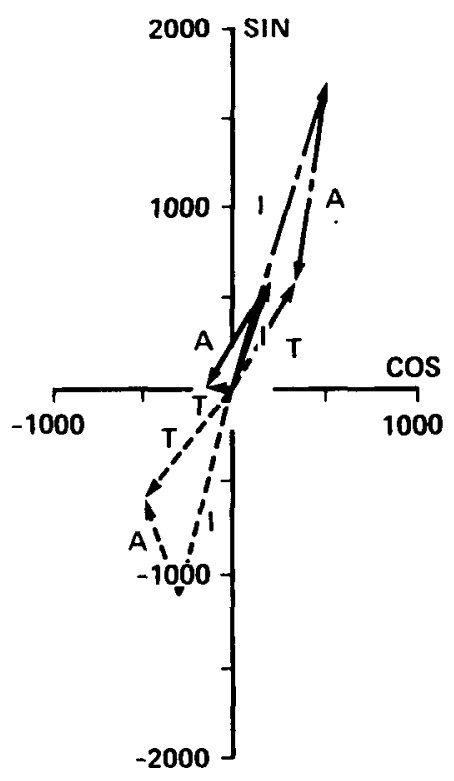

(b) $F_{Y}, 3 / R E V$

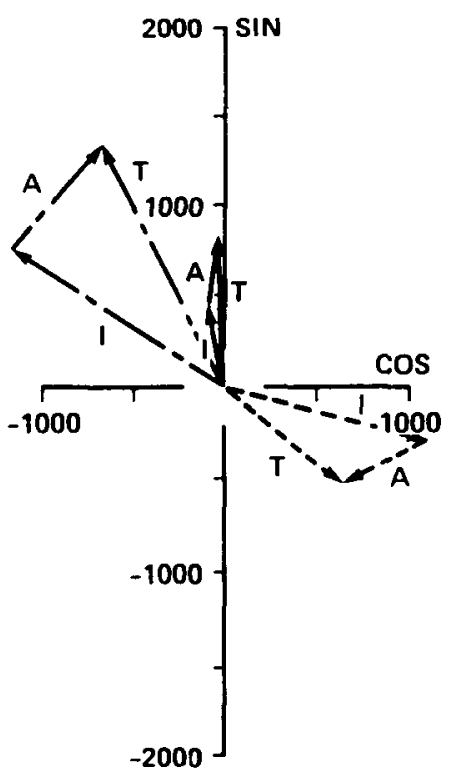

PERTURB. DUE TO HHC

$\longrightarrow$ PERTURB. DUE

$\longrightarrow$ WITH HHC (c) $F_{Z}, 3 /$ REV

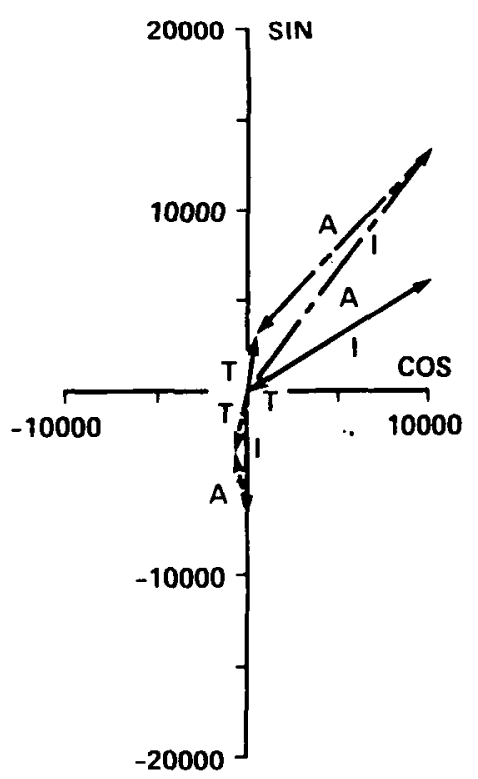

Figure 26. Influence of higher harmonic control on the amplitude and phase of the total (T) nonrotating-frame hub forces, and the inertial (I) and aerodynamic (A) components,
a. $3 /$ rev $F X$,
b. $3 /$ rev FY,

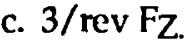




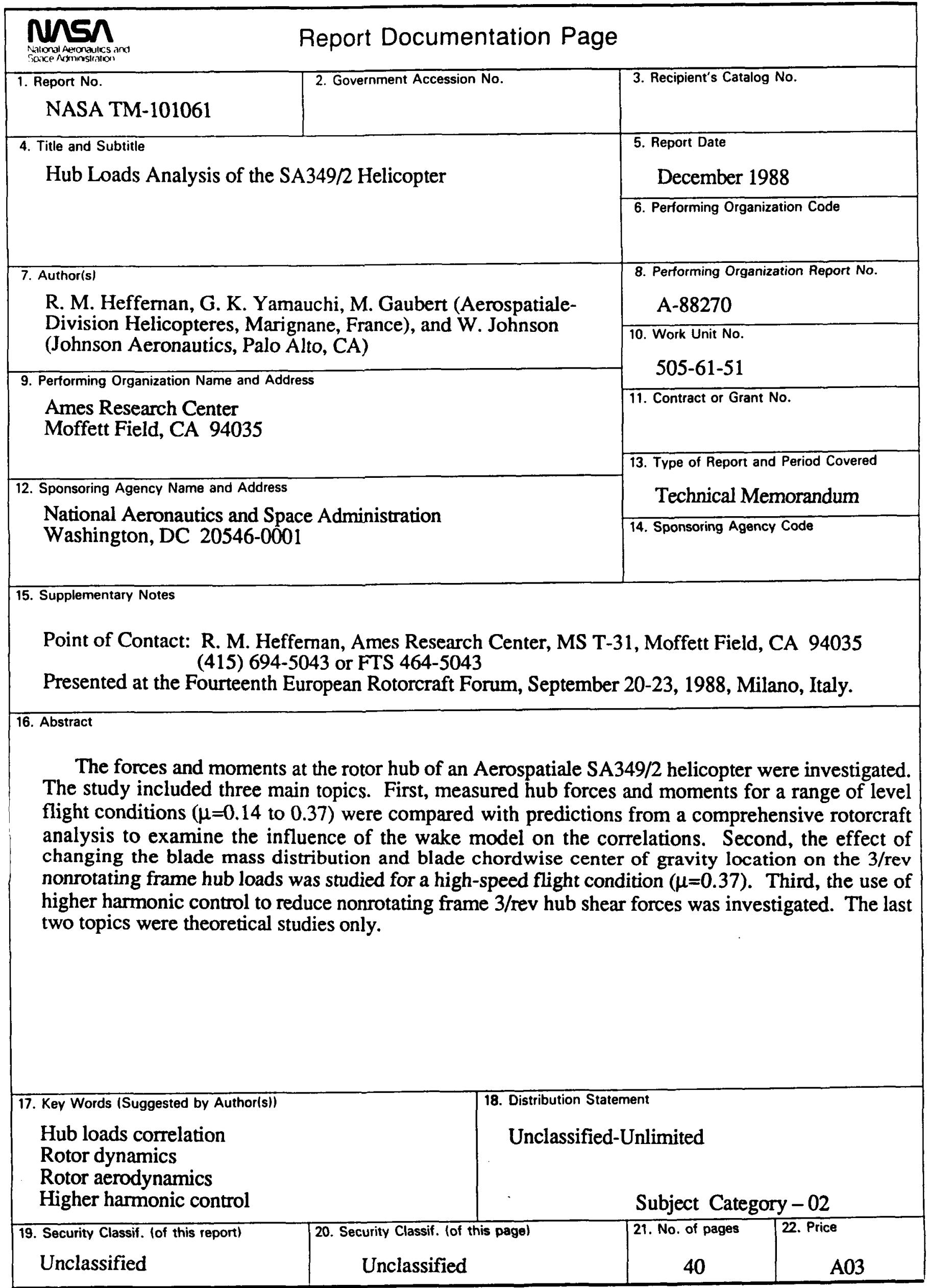




\section{PREPARATION OF THE REPORT DOCUMENTATION PAGE}

The last page of a report facing the third cover is the Report Documentation Page, RDP. Information presented on this page is used in announcing and cataloging reports as well as preparing the cover and title page. Thus it is important that the information be correct. Instructions for filling in each block of the form are as follows:

Block 1. Report No. NASA report series number, if preassigned.

Block 2. Government Accession No. Leave blank.

Block 3. Recipient's Catalog No. Reserved for use by each report recipient.

Block 4. Title and Subtitle. Typed in caps and lower case with dash or period separating subtitle from title.

Block 5. Report Date. Approximate month and year the report will be published.

Block 6. Performing Organization Code. Leave blank.

Block 7. Author(s). Provide full names exactly as they are to appear on the title page. If applicable, the word editor should follow a name.

Block 8. Performing Organization Report No. NASA installation report control number and, if desired, the nonNASA performing organization report control number.

Block 9. Performing Organization Name and Address. Provide affiliation ( $\bar{N} \bar{A} \bar{A} \bar{A}$ program office, $\bar{N} \bar{A} \overline{S A}$ installation, or contractor name) of authors.

Block 10. Work Unit No. Provide Research and Technology Objectives and Plans (RTOP) number.

Block 11. Contract or Grant No. Provide when applicable.

Block 12. Sponsoring Agency Name and Address. National Aeronautics and Space Administration, Washington, D.C. 20546-0001. If contractor report, add NASA installation or $\mathrm{HQ}$ program office.

Block 13. Type of Report and Period Covered. NASA formal report series; for Contractor Report also list type (interim, final) and period covered when applicable.

Block 14. Sponsoring Agency Code. Leave blank.

Block 15. Supplementary Notes. Information not included elsewhere: affiliation of authors if additional space is re- quired for block 9 , notice of work sponsored by another agency, monitor of contract, information about supplements (film, data tapes, etc.), meeting site and date for presented papers, journal to which an article has been submitted, note of a report made from a thesis, appendix by author other than shown in block 7 .

Block 16. Abstract. The abstract should be informative rather than descriptive and should state the objectives of the investigation, the methods employed (e.g., simulation, experiment, or remote sensing), the results obtained, and the conclusions reached.

Block 17. Key Words. Identifying words or phrases to be used in cataloging the report.

Block 18. Distribution Statement. Indicate whether report is available to public or not. If not to be controlled, use "Unclassified-Unlimited." If controlled availability is required, list the category approved on the Document Availability Authorization Form (see NHB 2200.2, Form FF427). Also specify subject category (see "Table of Contents" in a current issue of STAR), in which report is to be distributed.

Block 19. Security Classification (of this report). Self-explanatory.

Block 20. Security Classification (of this page). Self-explanatory.

Block 21. No. of Pages. Count front matter pages beginning with iii, text pages including internal blank pages, and the RDP, but not the titie page or the back of the title page.

Block 22. Price Code. If block 18 shows "UnclassifiedUnlimited," provide the NTIS price code (see "NTIS Price Schedules" in a current issue of STAR) and at the bottom of the form add either "For sale by the National Technical Information Service, Springfield, VA 22161-2171" or "For sale by the Superintendent of Documents, U.S. Government Printing Office, Washington, DC 20402-0001," whichever is appropriate. 